This is the final peer-reviewed accepted manuscript of:

Amato, J.; Morigi, R.; Pagano, B.; Pagano, A.; Ohnmacht, S.; De Magis, A.; Tiang, Y. P.; Capranico, G.; Locatelli, A.; Graziadio, A.; Leoni, A., Rambaldi, M.; Novellino, E.; Neidle, S.; Randazzo, A.

Toward the Development of Specific G-Quadruplex Binders: Synthesis, Biophysical, and Biological Studies of New Hydrazone Derivatives.

Journal of Medicinal Chemistry, 2016, 59 (12), 5706-5720.

The final published version is available online at: https://doi.org/10.1021/acs.jmedchem.6b00129

Rights / License:

The terms and conditions for the reuse of this version of the manuscript are specified in the publishing policy. For all terms of use and more information see the publisher's website. 


\section{Toward the development of specific G-quadruplex binders: synthesis, biophysical and biological studies of new hydrazone derivatives}

Jussara Amato, ${ }^{\dagger, \#}$ Rita Morigi, ${ }^{\ddagger, \#}$ Bruno Pagano, ${ }^{\dagger}$ Alessia Pagano, ${ }^{\dagger}$ Stephan Ohnmacht, ${ }^{\S}$ Alessio De Magis, ${ }^{\star}$ Yee-Peng Tiang, ${ }^{\ddagger}$ Giovanni Capranico, ${ }^{\star}$ Alessandra Locatelli, ${ }^{\star}$ Alessandra Graziadio, ${ }^{\star}$ Alberto Leoni, ${ }^{\star}$ Mirella Rambaldi, ${ }^{\ddagger}$ Ettore Novellino, ${ }^{\dagger}$ Stephen Neidle, ${ }^{\S}$ and Antonio Randazzo $*, \dagger$

${ }^{\dagger}$ Department of Pharmacy, University of Naples “Federico II", 80131 Napoli, Italy

${ }^{\ddagger}$ Department of Pharmacy and Biotechnology, University of Bologna, 40126 Bologna, Italy

${ }^{\S}$ UCL School of Pharmacy, University College London, London WC1N 1AX, UK

\#J.A. and R.M. contributed equally.

*Corresponding author. E-mail: antonio.randazzo@unina.it. Phone: (+39) 081678514.

KEYWORDS. G-quadruplex; Ligands; Anticancer; Telomeric DNA; Oncogene promoters. 
ABSTRACT: G-quadruplex-binding compounds are currently perceived as possible anticancer therapeutics. Here, starting from a promising lead, a small series of novel hydrazone-based compounds were synthesized and evaluated as G-quadruplex binders. The in vitro G-quadruplexbinding properties of the synthesized compounds were investigated employing both human telomeric and oncogene promoter G-quadruplexes with different folding topologies as targets. The present investigation led to the identification of potent G-quadruplex stabilizers with high selectivity over duplex DNA and preference for one G-quadruplex topology over others. Among them, selected derivatives have been shown to trap G-quadruplex structures in the nucleus of cancer cells. Interestingly, this behavior correlates with efficient cytotoxic activity in human osteosarcoma and colon carcinoma cells. 


\section{INTRODUCTION}

The interest in non-canonical DNA secondary structures as targets for novel and selective anticancer drugs is exponentially growing, in particular due to their involvement in a number of critical cancer-related genomic aberrations and pathways. ${ }^{1-3}$ G-quadruplexes (G4s) are now viewed as promising drug targets and much effort is currently underway to discover effective and selective ligands for them. ${ }^{2,4} \mathrm{G} 4 \mathrm{~s}$ are four-stranded structures composed of stacked guanine tetrads (Gtetrads) that can form within G-rich tracts of genomic DNA and depend on the presence of cations, especially $\mathrm{K}^{+}$and $\mathrm{Na}^{+}{ }^{5}$ G4-forming sequences are located in different critical positions of the human genome, notably at telomeres and in oncogene promoters. ${ }^{2,4}$

Telomeric regions at the chromosome ends comprise 2-20 kb of double-stranded TTAGGG repeats together with a 3' single-stranded overhang of 50-500 nucleotides which can readily adopt G4 structures. ${ }^{4,5}$ It is known that telomeres are involved in the regulation of cellular proliferation, and become gradually shorter, in parallel with normal cell proliferation, triggering replicative senescence, leading to irreversible cell-cycle arrest. ${ }^{6}$ Almost all cancer cells circumvent this problem by activating telomere-length maintenance mechanisms that facilitate their proliferation and survival. In about $85 \%$ of human tumors, the reverse transcriptase enzyme telomerase drives telomere maintenance by adding copies of the TTAGGG repeat motif to the end of the singlestranded overhang. ${ }^{7}$ In the remaining ca. $15 \%$ of cancer cells, the same result is obtained by a different mechanism known as alternative lengthening of telomere (ALT). ${ }^{8}$ The inhibitory effect of G4 formation at telomere ends on the activity of telomerase is well established. ${ }^{9}$ The effect of G4binding molecules, upon interaction with telomeric G4 DNA, is to induce G4 formation and then inhibit telomerase, ${ }^{4}$ and also in a number of instances to induce rapid onset of DNA damage responses, leading to cellular apoptosis. ${ }^{10}$

The presence of putative $\mathrm{G} 4 \mathrm{~s}$ in the promoter regions of a number of oncogenes (e.g. $c-M Y C, c$ $K I T, V E G F, R E T)$ and their function in transcriptional regulation is a more recent discovery that may have significant therapeutic implications. ${ }^{2}$ Indeed, compounds that can promote formation of 
G4s in oncogene promoters or modulate their stability could, in turn, regulate expression of the target gene. This has developed into a novel strategy for cancer drug discovery.

Many research groups have subsequently attempted to identify G4-binding compounds and to date, over 1000 ligands have been reported, representing a wide range of chemotypes. ${ }^{11,12}$ Some of these have been identified in order to target the grooves of G4 structures, although most have been devised to primarily stack on the external G-tetrads of G4s. ${ }^{11-15}$ The structural features that appear to facilitate the latter binding mode are: i) the presence of an extended planar aromatic scaffold that can efficiently stack on terminal G-tetrads through $\pi$ - $\pi$ stacking; ii) an electron-deficient aromatic core that can enhance stacking interactions on G-tetrads via cation- $\pi$ interaction: iii) the presence of cationic side-chains. These positively-charged tethered substituents can interact with the grooves and loops of G4, and with the negatively charged phosphate backbone.

In 2010, some of us reported that the bis-guanylhydrazone derivative of diimidazo[1,2-a:1,2c]pyrimidine 1 (Figure 1) was a potent stabilizer of several G4 DNAs, whereas no significant interaction with duplex DNA was found. ${ }^{16}$ Its high affinity and selective G4-stabilizing ability led us to consider $\mathbf{1}$ as a promising lead compound and to design a small series of analogues. Structural modifications of $\mathbf{1}$ involved in particular the guanyl chains, the substituents at positions 2 and 8 and the core chromophore itself (Figure 1). The guanyl groups have been modified by introducing a more rigid frame (2) or an aromatic system (4). Together with compound $\mathbf{2}$, the mono-hydrazone $\mathbf{3}$ was isolated from the reaction mixture, and has also been investigated. The phenyl rings at positions 2 and 8 have been replaced with the bioisostere thiophene to obtain compound $\mathbf{5}$. The tricyclic core has been substituted with different systems: the pyrroloindole nucleus to obtain compound $\mathbf{6}$ or a chloroindole moiety $(\mathbf{7}, \mathbf{8})$, to achieve core simplification and finally, core expansion was explored by introducing the planar bisindole system of indigo which was functionalized with iminoguanyl or hydrazinylpyridyl groups in order to obtain compounds 9 and $\mathbf{1 0 .}$

The in vitro G4-binding properties of the synthesized compounds were investigated employing both human telomeric and oncogene promoter G4s with different topologies as targets. The 
compounds that showed the best G4-binding properties in terms of specificity and stabilizing effects were further investigated employing biophysical methodologies. The subsequent analysis of the biological properties of selected compounds demonstrated that the molecular effects on G4 stability in living cells were associated with the biological activity of these hydrazone derivatives.

\section{RESULTS AND DISCUSSION}

\section{Chemistry}

The hydrazones 2-5 (Scheme 1) and 6-10 (Scheme 2) were prepared by reaction between an aldehyde or a ketone and the appropriate hydrazine: aminoguanidine hydrochloride, 2-hydrazino-2imidazoline hydrobromide or 2-hydrazino-2-pyridine hydrochloride. When this reaction was performed with 2-hydrazino-2-imidazoline on aldehyde $\mathbf{1 4 a},{ }^{17}$ in addition to the bis hydrazone $\mathbf{2}$, the mono hydrazone derivative $\mathbf{3}$ was isolated from the reaction mixture. Two nOe experiments were used to determine which aldehyde group reacted. The irradiation of the $\mathrm{CHO}$ at $10.09 \mathrm{ppm}$ provided a nOe correlation with one of the pyrimidine proton at $9.12 \mathrm{ppm}$, whereas when the $\mathrm{CH}=\mathrm{N}$ at $9.47 \mathrm{ppm}$ was irradiated, no nOe effect at the pyrimidine proton was observed. Taken together these two findings suggest that the unreacted $\mathrm{CHO}$ is at position 3.

All the hydrazones have been obtained as hydrochlorides or hydrobromides, in which, as previously reported, ${ }^{18}$ the side chains are protonated and the positive charge is delocalized on the nitrogens of the guanyl or of the imidazoline groups. Indeed, ${ }^{1} \mathrm{H}-\mathrm{NMR}$ spectra of guanylhydrazone derivatives display at about $8 \mathrm{ppm}$ a broad signal integrating to eight protons and exchanging after $\mathrm{D}_{2} \mathrm{O}$ addition, which may be ascribed to the two protonated guanyl groups. Similarly, the ${ }^{1} \mathrm{H}-\mathrm{NMR}$ spectra of compounds $\mathbf{2}$ and $\mathbf{3}$ show a broad signal at about $8.5 \mathrm{ppm}$ integrating to 2 protons due to the protonated imidazoline nitrogens. Interestingly, owing to protonation and charge delocalization,

the imidazoline ring become symmetric, therefore the two $\mathrm{CH}_{2}$ give only one ${ }^{1} \mathrm{H}-\mathrm{NMR}$ signal: a singlet that integrates to four protons. 
The new starting aldehydes 14b, 17, 20 and 21 were obtained by means of the Vilsmeier reaction on compounds 13b, 16, 18 and 19 (Scheme 1,2) performed under reflux in order to promote bisformylation. The bis-aldehydes $\mathbf{2 0}$ and $\mathbf{2 1}$ were isolated by column chromatography and the positions of the formyl groups were determined using nOe experiments. The aromatic signals of compound 20 were assigned by irradiating the methyl group at $3.93 \mathrm{ppm}$. nOe correlation was observed with the signal at $8.24 \mathrm{ppm}$, therefore this singlet was assigned to the proton at position 7 (ind-7). Afterwards, we proceeded by irradiating the $\mathrm{CHO}$ signals. When the $\mathrm{CHO}$ proton at 10.03 ppm was irradiated, no nOe effect was observed, thus this signal was assigned to the $\mathrm{CHO}$ group at position 3. On the other hand, irradiation at $10.07 \mathrm{ppm}$ provided a nOe with signals at $8.24 \mathrm{ppm}$ (ind-7) and $7.83 \mathrm{ppm}$ (ind-5), thus indicating that this $\mathrm{CHO}$ group is at position 6. Similar nOe experiments performed on compound $\mathbf{2 1}$ confirmed that, even in this case, the $\mathrm{CHO}$ groups are at positions 3 and 6.

Compound 13b (Scheme 1) was obtained in two steps by reacting pyrimidine-2,4-diamine 11 (commercially available) with 2-bromo-1-(thiophen-3-yl)ethan-1-one. As observed for the previously described compound $\mathbf{1 2 a},{ }^{19}$ the first cyclization involved the nitrogen at position 1 and the amino group at position 2, and led to the bicyclic compound $\mathbf{1 2 b}$ whose structure was determined by two nOe experiments. The first experiment confirmed the spatial closeness of the pyrimidine proton at position 6 and $\mathrm{NH}_{2}$ as suggested by nOe correlation between the doublet at $6.37 \mathrm{ppm}(\mathrm{H}-6 \mathrm{pym})$ and the signals at $8.36 \mathrm{ppm}$ (the other pyrimidine signal) and $7.16 \mathrm{ppm}\left(\mathrm{NH}_{2}\right)$. The second nOe experiment, performed by irradiating on the doublet at $8.36 \mathrm{ppm}$, provided a correlation with the signals at $6.37 \mathrm{ppm}(\mathrm{H}-6 \mathrm{pym})$ and $7.74 \mathrm{ppm}$ (im), thus confirming the structure of $\mathbf{1 2 b}$. An attempt to prepare 13b directly from 11 with excess of 2-bromo-1-(thiophen-3-yl)ethan1-one was unsuccessful: the intermediate $\mathbf{1 2 b}$ is formed as the hydrobromide and it was necessary to prepare the corresponding base before treating it again with 2-bromo-1-(thiophen-3-yl)ethan-1one. 
Compound 16 (Scheme 2) was obtained in two steps treating $N, N^{\prime}$-dimethylbenzene-1,3-diamine (15) with chloroacetyl chloride in order to achieve the acylation of the amino groups. Afterwards, the intermediate thus obtained was cyclized by Friedel Crafts alkylation with $\mathrm{AlCl}_{3}$. The other starting materials, 2-bromo-1-(thiophen-3-yl)ethan-1-one, 14a, 15, 18, 19, 22, were prepared according to the literature. ${ }^{17,20-24}$

\section{Circular dichroism studies}

In order to evaluate the interaction of compounds 1-10 with G4 structures, several diverse G4forming sequences able to form parallel, antiparallel and hybrid G4 structures were selected for this study. It is known that human telomeric DNA G4s can adopt different topologies depending on the selected sequence and experimental conditions. ${ }^{25}$ In this study, two human telomeric DNA sequences, namely Tel23 and Tel26, were used. They are known to form the so-called hybrid-1 and hybrid-2 folds, respectively. In addition, since several studies suggest the parallel G4 fold ${ }^{26}$ as the prevalent one in the overcrowded solution conditions present inside a cell, ${ }^{27}$ we also prepared a Tel23 sample at high DNA concentration conditions in order to promote the parallel G4 conformation (hereafter referred to as Tel23-p, see Experimental Section). Further, to determine the affinity of the ligands toward other G4 structures, the two G4-forming sequences from the nuclease hypersensitive region of the $c$-KIT promoter (c-kit1 and c-kit2) and one from the $c-M Y C$ promoter (c-myc) were also used.

The structures adopted by each G4 sample were verified by circular dichroism (CD) spectroscopy. Tel23-p, c-kit1, c-kit2 and c-myc displayed a positive band at $264 \mathrm{~nm}$ and a negative one around $240 \mathrm{~nm}$ in the CD spectrum (Figure S1). These bands are characteristic of parallelstranded G4 topologies. ${ }^{28}$ On the other hand, Tel23 and Tel26 showed very similar CD spectra having a positive band at 289 with a shoulder at ca. $268 \mathrm{~nm}$, and a weak negative band at around $240 \mathrm{~nm}$ (Figure S1). These data are consistent with the presence of hybrid structures as major conformations. 
$\mathrm{CD}$ experiments were also performed to examine the potential of compounds $\mathbf{1 - 1 0}$ to alter the native folding topology of these G4s. Thus, DNA/ligand complexes were obtained by adding ligands (4 molar equiv.) to the folded G4 structures. No significant variations of CD signal were observed for any of the structures analyzed here (Figure S1), suggesting an overall preservation of their G4 architectures upon the addition of each ligand.

The structure of a duplex DNA (ds12), which is formed by a self-complementary 12-nt sequence, was also verified by CD spectroscopy, since it has been used in subsequent experiments to evaluate the selectivity of the ligands for G4 over duplex DNA (see below). In the presence of $\mathrm{K}^{+}$, the CD spectrum of ds12 was characterized by a positive band at around $280 \mathrm{~nm}$ and a negative one at $250 \mathrm{~nm}$, typical of values observed for duplex DNA (Figure S1). These bands were not modified upon ligand addition.

\section{CD melting studies}

The stabilizing properties of the compounds were evaluated by CD-melting experiments measuring the ligand-induced change in the melting temperature $\left(\Delta \mathrm{T}_{\mathrm{m}}\right)$ of $\mathrm{G} 4$ and duplex structures. CD-melting curves of DNAs in the absence and presence of each ligand were obtained by following the variations of the intensities of CD signals at the wavelength of 264, 290 and $280 \mathrm{~nm}$ for parallel G4s, antiparallel G4s and duplex, respectively (Figure S2). For the first CD-melting experiments, a 4:1 ligand/DNA ratio was used, so that all possible G4 binding sites were available. Results of these experiments are reported in Table 1. On the basis of these data, ligands have been ranked in the following categories: i) compounds that exhibit poor G4-stabilizing properties toward any $\mathrm{G} 4\left(\Delta \mathrm{T}_{\mathrm{m}}\right.$ $<5{ }^{\circ} \mathrm{C}$ ) (compounds 4 and 10); ii) compounds showing medium G4-stabilizing effect $\left(\Delta \mathrm{T}_{\mathrm{m}}=5-15\right.$ ${ }^{\circ} \mathrm{C}$ ) (compound 9); and iii) potent $\mathrm{G} 4$ stabilizers $\left(\Delta \mathrm{T}_{\mathrm{m}}>15^{\circ} \mathrm{C}\right)$ (compounds $\left.2, \mathbf{3 , 5 - 8}\right)$. As with the lead compound $\mathbf{1}$, most of the compounds investigated here showed high selectivity for G4 over duplex DNA. However, compounds 6, 7 and 8, having a different core from compound 1, were the only ligands to significantly increase duplex stability, and therefore were not considered to be 
selective. Interestingly, compounds 2, 3 and 5 showed some preference for parallel G4s over antiparallel ones. In particular, compound $\mathbf{3}$ stabilized to a large extent only the c-myc G4 $\left(\Delta \mathrm{T}_{\mathrm{m}}>\right.$ $20{ }^{\circ} \mathrm{C}$ ). Since we were mainly interested in finding G4 ligands specific for one topology, or, even better, for one structure, further studies were only performed on compounds $\mathbf{2}, \mathbf{3}$ and $\mathbf{5}$. Therefore, we carried out CD melting experiments to investigate the effect of increasing concentrations of $\mathbf{2 , 3}$ and $\mathbf{5}$ on the stability of both c-kit2 and c-myc G4s (Figure 2). Three different [ligand]/[DNA] ratio were examined (1:1, 2:1 and 4:1). In the case of c-kit2, we observed a dose-dependent increase of thermal stability for all three compounds although with some differences between them. In particular, compounds $\mathbf{2}$ and $\mathbf{5}$ increased the $\mathrm{T}_{\mathrm{m}}$ of the G4 with every addition of ligand, while $\mathbf{3}$, which had shown a modest increase in c-kit2 stability, did not induce any further increase of $\mathrm{T}_{\mathrm{m}}$ beyond the 2:1 [ligand]/[DNA] ratio. In the case of c-myc, increasing thermal stability of the G4 with compound 3 also ceased at a 2:1 ratio, but after a considerable increase of $T_{m}$. On the other hand, concentration-dependency was observed for $\mathbf{2}$ (although slight compared to c-kit2), while the high G4-stabilizing effect of $\mathbf{5}$ on c-myc did not enable us to assess any dose-dependent effects.

Overall, these results indicate that six out of nine synthesized ligands are potent G4 stabilizers. The diimidazo[1,2-a:1,2-c]pyrimidine derivatives having a positive charge on the side chain(s) in the used experimental conditions (i.e. 2, 3 and 5) showed high affinity toward some of the investigated G4 structures. Conversely, compound 4, whose side chain protonation is less favorable at $\mathrm{pH}$ 7.0, showed generally poor G4-stabilizing properties. In any case, beyond the overall charge of these ligands, their duplex-binding activity is negligible. Concerning the compounds with a different core, the positively charged ones $(\mathbf{6}, 7$ and 8 ) showed affinity for some of the G4s investigated as well as for duplex DNA. On the other hand, compounds $\mathbf{9}$ and 10, whose side chain protonation is less likely to occur at $\mathrm{pH}$ 7.0, showed medium to low G4-stabilizing properties and negligible effects on duplex. In summary, these results indicate that the overall charge of compounds is important in DNA binding, but, at the same time, suggest that the charge is necessary but not sufficient to ensure potent and selective interaction with a specific DNA structure. 
In addition, $\mathrm{CD}$ melting data suggest that two molecules of $\mathbf{3}$ could bind and stabilize the G4 target (the addition of more than two equivalents of ligand does not lead to a further enhancement of G4 stability), possibly interacting in an end-stacking mode at the terminal G-tetrads of the G4 (see also NMR and molecular docking sections), a common binding mode exhibited by the majority of effective G4-targeting ligands.

It has to be noted that a significant destabilizing effect on Tel23 and Tel26 G4s occurs with some ligands. In particular, this phenomenon occurs with compounds $\mathbf{1}, \mathbf{2}$ and $\mathbf{5}$, namely the bishydrazone derivatives of diimidazo[1,2-a:1,2-c]pyrimidine. The mechanism of destabilization of these G4 structures by such derivatives is unclear and would need further study. However, we hypothesize that it may involve non-specific interactions of compounds with the DNA molecule that might favor single-stranded DNA, resulting in a shift of folded-unfolded equilibrium towards the unfolded form during the melting experiment, which, in turn, may result in a decrease of $\mathrm{T}_{\mathrm{m}}$.

\section{FRET melting studies}

The FRET methodology was also used to evaluate the investigated compounds and to estimate their G4 vs duplex selectivity. ${ }^{29}$ The compounds were first screened with the derivatized human telomeric G4 sequence F21T and a duplex DNA sequence (T-loop) by using various concentrations of ligands. Similarly to the lead $\mathbf{1}$, compounds $\mathbf{2}, \mathbf{3}$, and 5-8 showed potent G4 stabilizing capabilities, while compounds $\mathbf{4}, \mathbf{9}$, and $\mathbf{1 0}$ produced no significant change in G4 melting

temperature (Figure S3). Among the effective G4 stabilizers, compounds $\mathbf{6}, \mathbf{7}$ and $\mathbf{8}$ showed a significant degree of duplex stabilizing ability, confirming once again their low selectivity for G4 over duplex DNA. On the other hand, FRET results also confirm that compounds $\mathbf{2}, \mathbf{3}$, and $\mathbf{5}$ are effective and selective stabilizers of the G4 structures.

However, the results of these FRET melting experiments cannot be directly compared with those obtained from CD melting studies because of differences in DNA sequences and in experimental conditions. Therefore, to more fully compare the results of CD melting experiments obtained for compounds 2, 3 and 5, additional FRET melting experiments were performed on these ligands 
under the same buffer conditions used for $\mathrm{CD}$, using as targets the labeled G4-forming oligonucleotides from the $c-K I T$ (Fckit2T) and $c-M Y C$ (FcmycT) promoter regions, and the telomeric G4-forming sequence annealed at high concentration to promote the parallel conformation (F21T-p) (Figure S4). The results of FRET melting experiments, shown in Table 2, are in good qualitative agreement with those obtained from CD melting studies. The FRET ranking order reflects that compared to the CD melting data; the fact that the $\Delta \mathrm{T}_{\mathrm{m}}$ values themselves are somewhat different, is likely to be a consequence of different techniques and does not have particular significance.

\section{CD titration experiments}

$\mathrm{CD}$ has been also used to investigate the ability of the best ligands $(\mathbf{2}, \mathbf{3}$, and $\mathbf{5})$ to induce $\mathrm{G} 4$ formation from unfolded single-stranded DNAs, by performing CD titration experiments in the absence of metal ions. In particular, the sequences c-kit1, c-kit2, Tel23 and c-myc in $50 \mathrm{mM}$ Tris buffer were investigated. The CD spectra of c-kit1 and c-kit2 sequences in the absence of monovalent metal cations showed a positive band at around $262 \mathrm{~nm}$ and a negative one around 240 $\mathrm{nm}$, that, even if small, are indicative of the presence of a small percentage of a parallel G4 structure in solution (Figure S5). Upon addition of ligands to G4s, a dose-dependent increase of the $\mathrm{CD}$ bands was observed in some case, suggesting the induction of the parallel G4 structure formation. In particular, as far as c-kit2 is concerned, compounds $\mathbf{2}$ and $\mathbf{5}$ caused a major increase of ellipticity compared to $\mathbf{3}$. Similarly, the addition of $\mathbf{2}$ and $\mathbf{5}$ to the c-kit1 sequence also caused a dose-dependent increase in CD signals (more intense for $\mathbf{5}$ ), whereas the addition of $\mathbf{3}$ did not affect the $\mathrm{CD}$ profile, thus indicating that $\mathbf{3}$ is unable to induce c-kit1 G4 formation.

The c-myc G4 DNA sequence exists in a parallel topology, in the absence of any added monovalent metal cation, showing a positive band at $263 \mathrm{~nm}$ and a negative one around $240 \mathrm{~nm}$. The addition of ligands $\mathbf{2}, \mathbf{3}$ and $\mathbf{5}$ to c-myc G4 did not perturb the parallel G4 structure already formed in Tris buffer. On the other hand, the addition of compounds 2, 3 and $\mathbf{5}$ to the Tel23 
sequence did not lead to any increase in CD ellipticity, thus suggesting that none of them is able to induce any telomeric G4 structures.

In summary, these results suggest that $\mathbf{2}$ and $\mathbf{5}$ are able to induce the c-kit1 and c-kit 2 sequences to form G4 structures in the absence of metal cations. On the other hand, compound $\mathbf{3}$, which is an unexceptional binder of c-kit G4s, does not induce the formation of any G4 structure. Finally, none of the ligands showed an inducing effect on the telomeric G4-forming sequence.

\section{Nuclear magnetic resonance studies}

NMR spectroscopy was employed in order to obtain structural information about the binding mode of compound 3. As stated above, this compound is a potent and specific stabilizer of c-myc G4. Since the wild-type G4 sequence of c-myc is not suitable for study by NMR (its ${ }^{1} \mathrm{H}-\mathrm{NMR}$ spectrum is affected by the presence of minor conformations), the well-characterized modified sequence (Myc22) containing two G-to-T mutations at position 14 and 23, was used for the NMR titration experiments. The spectral regions of the imino and aromatic protons in the absence and presence of increasing amounts of compound $\mathbf{3}$ are shown in Figure 3A. According to the literature, under the experimental conditions used, the Myc22 DNA sequence forms a single G4 conformation characterized by 12 well-resolved imino protons peaks, corresponding to the 12 guanines involved in the three G-tetrad planes. ${ }^{30}$ Upon addition of compound $\mathbf{3}$ to the Myc22 solution, both imino and aromatic protons became broad even at higher drug equivalence, indicating a dynamic binding process of $\mathbf{3}$ to Myc22 with a medium exchange rate on the NMR time-scale. The titration was virtually complete at a ligand/DNA ratio of 2:1. Major chemical shift changes were observed for the imino protons belonging the $5^{\prime}$ G-tetrad (G7-G11-G16-G20) as well as for G9 of the 3' G-tetrad (G9-G13-G18-G22), while the remaining imino protons of G13, G18 and G22 at the $3^{\prime}$-end tetrad and those of middle tetrad (G8-G12-G17-G21) were less affected. The origin of this different behavior could be due to inherent structural features associated with the 3'- and 5'-faces as well as the flanking sequences. The 5' side is more accessible for ligand stacking and the only $5^{\prime}$-flanking 
residue particularly affected by the binding turned out to be the $\mathrm{T} 4$, as shown by the corresponding aromatic proton shift. By contrast, the 3'-face is less accessible. A25 from this side folds back to form a base pair with T23 to cover the external G-tetrad, while A24 stays above the T23:A25 base pair. However, these latter flanking residues are not able to completely prevent the binding. Upon addition of $\mathbf{3}$, the aromatic protons of T23, A24 and A25 were strongly perturbed, suggesting that the ligand can be positioned between the four guanines of the $3^{\prime}$-tetrad and the $3^{\prime}$-flanking bases. The stability of the $3^{\prime}$-end bound ligand complex with Myc22 could be related to the possibility of specific H-bond interactions between the imidazole group of $\mathbf{3}$ and the $3^{\prime}$-flanking bases (as discussed in the docking section).

For comparison, we have also examined the binding behavior of 3 to the c-kit2 G4. Since the ckit2 G4 wild-type sequence gives poorly resolved imino proton NMR spectra, we used the modified sequence c-kit $2_{\mathrm{T} 12 / \mathrm{T} 21}$ (in which $\mathrm{G} 12$ and $\mathrm{G} 21$ are replaced by two $\mathrm{T}$ residues), which is known to fold into a monomeric parallel G4 structure with well-resolved imino proton signals. ${ }^{31,32}$ Figure $3 \mathrm{~B}$ shows the spectral regions of the imino and aromatic protons of c-kit $2_{\mathrm{T} 12 / \mathrm{T} 21}$ in the absence and presence of increasing amounts of compound 3. Interestingly, the imino signals belonging to the Gtetrad on the $5^{\prime}$-side (G2, G6, G14 and G18) were equally affected with respect to those belonging to the $3^{\prime}$-terminal G-tetrad, as well as the aromatic protons of $\mathrm{C} 1$ and A13 on the 5'-face and those of C9 and T21 on the 3'-face. These results clearly suggest an involvement of both external Gtetrads in binding, despite the potential pairing between residues $\mathrm{C} 1$ and $\mathrm{A} 13$ on the $5^{\prime}$-side. ${ }^{31}$ Thus, we hypothesize that 3 is able to interact with both the $5^{\prime}$ and $3^{\prime}$ G-tetrads, possibly by displacing the $\mathrm{C} 1$ and A13 base pairing at the former.

Overall these findings suggest that compound 3 binds to the $5^{\prime}$ - and $3^{\prime}$-terminal G-tetrads of both Myc22 and c-kit $2_{\mathrm{T} 12 / \mathrm{T} 21} \mathrm{G} 4 \mathrm{~s}$. However, some differences in the binding to the two G4s were observed, that could explain the difference in the thermal stabilization of the two G4s upon binding observed by CD analysis. Particularly, we speculate that this different binding behavior is due to the 
possibility of $\mathbf{3}$ forming specific H-bond interactions with Myc22 (see molecular docking section), thus ensuring that compound 3 binds more effectively to the c-myc G4 rather than to the c-kit2 G4.

\section{Molecular docking}

Molecular docking calculations were performed to provide a possible molecular basis for the G4 binding of 3. We docked the ligand to the three-dimensional structures of c-kit2 and c-myc G4s determined by solution state NMR spectroscopy. ${ }^{32,33}$ Taking into account the experimentally suggested binding stoichiometry, 2:1 (ligand/DNA) complex models were built with the G4 targets. Both 5'- and 3'-terminal G-tetrads were considered as potential binding sites for the ligand and were therefore examined in the docking procedures. For each binding site, the most favorable complex was selected from the docked structures on the basis of the calculated binding energies. The low-energy binding poses for the ligand are shown in Figure 4A and 4B.

The shape of $\mathbf{3}$ effectively fills much of the available space in the plane of the two G-tetrads in the c-myc G4. The tricyclic diimidazo[1,2-a:1,2-c]pyrimidine moiety is stacked onto the planes at a $3.4 \AA$ separation at both $5^{\prime}-$ and $3^{\prime}$-faces, and overlaps part of two guanine bases (G11 and G16 at the 5' G-tetrad; G9 and G13 at the 3' G-tetrad) making extensive $\pi$-stacking interactions (Figure 4A). In both cases, one of the two attached phenyl rings overlap part of a guanine of the tetrad, contributing to the stabilization, while the other one is twisted out of the diimidazo[1,2-a:1,2c]pyrimidine plane. The 2-hydrazino-2-imidazoline groups of the two ligand molecules make close hydrogen bonds with the oxygen atoms of the backbone phosphate groups of the G4. Noteworthy, the formyl group of $\mathbf{3}$ is, in both cases, hydrogen bonded to the first flanking base (A6 and T23 at $5^{\prime}-$ and $3^{\prime}$-end, respectively) that stacks over the G-tetrad, thus forming a plane capping the $5^{\prime}$ and 3' external G-tetrads of the c-myc G4.

In the case of c-kit2 G4, different binding poses were observed for the ligand on the two external G-tetrad surfaces (Figure 4B). Indeed, the molecular model of 3 bound to the c-kit2 G4 shows that at the $3{ }^{\prime}$-end, the planar aromatic scaffold of the ligand makes $\pi$-stacking interactions with the 3 ' G- 
tetrad, while the 2-hydrazino-2-imidazoline group is positioned to participate in a hydrogen bond with a phosphate group. However, by contrast with the c-myc G4, compound $\mathbf{3}$ does not form any additional interaction to further stabilize the complex. On the other hand, the docking calculations at the $5^{\prime}$-face of the c-kit2 G4 structure reveal that to make hydrogen-bonding/electrostatic contacts between the charged 2-hydrazino-2-imidazoline group and the backbone phosphate groups of the G4, the side chain of compound $\mathbf{3}$ needs to be located in the deep groove formed by the long loop 2 of the G4. As a consequence, the diimidazo[1,2-a:1,2-c]pyrimidine core of 3 results in not being parallel to the plane of the terminal G-tetrad. This is probably due to the $5^{\prime}-3^{\prime}$ strand polarity generated by the propeller loop topology of this G4, which does not expose the phosphodiester backbone on this side, thus making only the $3^{\prime}$-end more favorable to interact with ligands with positively-charged side chains.

Overall, the docking results reveal that $\mathbf{3}$ has the appropriate shape and electronic structure to form specific interactions. Interestingly, the binding of $\mathbf{3}$ could involve the first flanking bases to form a plane covering the external G-tetrads and contributing greatly to the G4 stabilization. This could also explain the selectivity of $\mathbf{3}$ in increasing the thermal stability of the c-myc G4.

Cytotoxic activity and stabilization of G4 structures by selected hydrazone derivatives in human cancer cells

As the studied hydrazone derivatives showed distinct specificity for different G4 structures, we next determined the effects of selected compounds at cellular levels. We selected compound $\mathbf{3}$ as it was the most selective agent in vitro, and we compared its effects with those of $\mathbf{1}$ (the lead) and 14a (Scheme 1, used as a negative control since it is unable to bind G4s in vitro). ${ }^{16}$ First, we determined the cell killing activity of the three selected molecules with the MTT assay in two human cancer cell lines: the osteosarcoma U2OS and colon cancer HCT116 lines. In this assay, after exposure to the compounds, cells were allowed to recovery in drug-free medium for $24-48$ hours before adding MTT to measure surviving cells (see Experimental Section). HCT116 cells were more sensitive 
than U2OS cells to the tested compounds, however both cell lines were more sensitive to compound 3 than other agents (Table 3). In particular, compound $\mathbf{3}$ showed high cell killing activity in U2OS cells after 24 hours of treatment $\left(\mathrm{IC}_{50}=0.845 \mu \mathrm{M}\right)$. In addition, 3 was 20 - and 12-fold more cytotoxic than compounds $\mathbf{1}\left(\mathrm{IC}_{50}=15.97 \mu \mathrm{M}\right)$ and $\mathbf{1 4 a}\left(\mathrm{IC}_{50}=9.16 \mu \mathrm{M}\right)$, respectively. Similarly, 3 was more cytotoxic than compounds $\mathbf{1}$ and $\mathbf{1 4 a}$ after 1 hour of cell treatment (Table 3).The sensitivity pattern was very similar in HCT116 cells, with compound $\mathbf{3}$ showing highest cell killing activity as compared with compounds 1 and $\mathbf{1 4 a}$ both after 24 hours and 1 hour of treatment (Table 3). Therefore, the results established that compound $\mathbf{3}$ is more cytotoxic than the other tested compounds, at least in the two cell lines used here.

Next, to show whether $\mathbf{3}$ and $\mathbf{1}$ stabilized G4s in living cells, we visualized nuclear G4 structures in human U2OS cells by immunofluorescence microscopy using the BG4 antibody, a known specific antibody against G4s. ${ }^{34}$ U2OS cells were treated for 24 hours with compound concentrations very close to the established $\mathrm{IC}_{50}$ values (Table 3). Immediately after treatments with tested compounds, cell death was minimal, as determined by cell FACS analyses and microscopy visualization (data not shown). After incubation with BG4 antibody, the fluorescence signal was generated by a final incubation with a fluorochrome-labeled antibody, and measured and analyzed with ImageJ as described in details in Experimental Section. BG4 showed nuclear staining in control, untreated cells indicating that G4 structures were present at discrete chromatin sites in the nucleus (Figure 5A), in agreement with previous studies. ${ }^{34}$ Fluorescence spots were of different sizes, and larger spots apparently consisted of a few smaller spots. The fluorescence patterns were similar in cells treated with the three selected hydrazone derivatives. However, the compound effects were very different since compounds $\mathbf{3}$ and $\mathbf{1}$, but not 14a, markedly increased the number, size and fluorescence intensity of nuclear spots, thus indicating that they could stabilize G4 structures in the nucleus of living cells. We then measured the total fluorescence signal per cell for each sample, and the results indicated that $\mathbf{3}$ was the most potent as an increase of G4 signal was detected even at $0.2 \mu \mathrm{M}$ (a dose 4-fold lower than $\mathrm{IC}_{50}$ ), and further increased at $1 \mu \mathrm{M}$, of 3 . 
Compound 1 was able to increase the nuclear G4 signal at $10 \mu \mathrm{M}$ at comparable levels as $\mathbf{3}$ at 0.2 $\mu \mathrm{M}$ (Figure 5A). In contrast, 14a did not show any increase in fluorescence intensity at the tested concentrations (Figure 5B). Statistical analyses showed that a significant increase of G4 after 0.2 $\mu \mathrm{M}\left(p=2.05 \times 10^{-32}\right)$ and $1 \mu \mathrm{M}\left(p=1.82 \times 10^{-55}\right)$ of compound 3 , and $10 \mu \mathrm{M}\left(p=2.44 \times 10^{-38}\right)$ of

1. Taken together, these data demonstrate that hydrazone derivatives can stabilize G4s in cultured human cancer cells, and that $\mathbf{3}$ is the most potent agent among the studied derivatives. Although we detected an association of cytotoxic potency with G4 stabilization in living cells among the tested compounds, further investigations at the cellular level are needed to establish a clear link between G4 stabilization and biological activity of these hydrazone derivatives.

\section{CONCLUSIONS}

Starting from the lead compound $\mathbf{1}$, a series of analogues with structural modifications of the substituents and the core have been designed, synthesized, and evaluated as effective and selective G4 binding ligands. The present study extends our previous work in which a hydrazone derivative was identified as a novel G4-binding motif, and provides the basis for the design of other analogues with improved binding properties. The results from $\mathrm{CD}$ assays showed that six out of nine synthesized ligands are potent G4 stabilizers that retain the pre-existing architecture of the target G4s upon interaction. However, the compounds having a different core from that of compound $\mathbf{1}(\mathbf{6}$, 7 and 8) were also shown to increase the stability of duplex DNA, and therefore they are not selective for G4s. On the other hand, compounds $\mathbf{2}, \mathbf{3}$ and $\mathbf{5}$ displayed a marked preference for binding to parallel G4s over duplex and antiparallel G4s. Interestingly, although not able to induce the formation of any G4 structure, compound $\mathbf{3}$ is found to be the most selective of the series. Therefore, it was investigated in detail in terms of binding mode. NMR experiments suggested an end-stacking binding mode at the terminal G-tetrads of the G4 with a 2:1 drug/DNA binding stoichiometry. Molecular docking results provided further insight into the recognition between $\mathbf{3}$ and the G4 DNA, highlighting the possible key structural elements involved in the interaction. 
Interestingly, compound $\mathbf{3}$, which is the only mono-hydrazone of the series, appears to have the appropriate structure to stack on the planar G-tetrad surfaces of c-myc G4 with the tricyclic diimidazo[1,2-a:1,2-c]pyrimidine core and, at the same time, to make (i) close hydrogenbonding/electrostatic contact between the charged 2-hydrazino-2-imidazoline group and the oxygen atoms of the backbone phosphate of G4, and (ii) a hydrogen bond interaction between the formyl group at position 3 and the hydrogen-bond donor groups of the first flanking base that stacks on the G-tetrad. Similar intermolecular interactions were also found in the structure of the complex between the quindoline molecule and c-myc $\mathrm{G} 4,{ }^{33}$ and could be the molecular determinants for specific G4 recognition. It is noteworthy that decreasing the number of positively-charged side chains leads to a significant benefit in terms of selectivity, without affecting the G4 stabilizing property of this derivative. In line with the in vitro assays, biological experiments demonstrated that hydrazone derivatives can effectively trap G4 structures in the nuclei of cells. Remarkable, derivative $\mathbf{3}$ is more effective than the lead compound $\mathbf{1}$ in inhibiting human U2OS and HCT116 cancer cell growth, as well as in stabilizing G4s in osteosarcoma cells. Altogether, the reported results indicate that this molecular scaffold could actually form the basis for the development of highly-selective drug-like G4 ligands with superior biological activity, to accomplish the desired result of achieving new and effective anticancer drug candidates.

\section{EXPERIMENTAL SECTION}

\section{Chemistry}

All the compounds prepared were at least $98 \%$ pure as determined by combustion analysis. Melting points are uncorrected. TLC was performed on Bakerflex plates (Silica gel IB2-F) and column chromatography on Kieselgel 60 (Merck): the eluent was a mixture of petroleum ether/acetone in various proportions. IR spectra were recorded in nujol on a Nicolet Avatar 320 E.S.P.; $v_{\max }$ is expressed in $\mathrm{cm}^{-1} .{ }^{1} \mathrm{H}-\mathrm{NMR}$ spectra were recorded on a Varian MR $400 \mathrm{MHz}$ (ATB PFG probe); the chemical shift (referenced to solvent signal) is expressed in $\delta$ (ppm) and $\mathbf{J}$ in $\mathrm{Hz}$ 
(abbreviations: ar=aromatic, im=imidazole, $\mathrm{ph}=$ phenyl, $\mathrm{py}=$ pyridine, $\mathrm{pym}=$ pyrimidine, th=thiazole, imi=imidazoline). The IR, ${ }^{1} \mathrm{H}-\mathrm{NMR}$ and ${ }^{13} \mathrm{C}-\mathrm{NMR}$ spectra of the compounds are in agreement with the assigned structures. 2,4-Diaminopyrimidine $\mathbf{1 1}$ is commercially available. The following compounds were prepared according to the literature: 2-bromo-1-(thiophen-3-yl)ethan-1-one, ${ }^{20}$ $\mathbf{1 4 a},{ }^{17} 15,{ }^{21} \mathbf{1 8},{ }^{22} \mathbf{1 9},{ }^{23}$ and $22 .{ }^{24}$

\section{Synthesis of 2-(thiophen-3-yl)imidazo[1,2-a]pyrimidin-7-amine (12b) (Scheme 1)}

2,4-Diaminopyrimidine 11 (10 mmol) was dissolved in $40 \mathrm{~mL}$ of acetone and treated with 2bromo-1-(thiophen-3-yl)ethan-1-one $(15 \mathrm{mmol})$. The reaction mixture was refluxed for $3 \mathrm{~h}$ and the resulting precipitate (12b hydrobromide) was collected by filtration. The free base was obtained by treatment with $15 \% \mathrm{NH}_{4} \mathrm{OH}$. The resulting precipitate was collected by filtration and crystallized from ethanol. Yield 46\%; mp 285-290 ${ }^{\circ} \mathrm{C}$; IR $\left(\mathrm{cm}^{-1}\right)$ : 3148, 1667, 1087, 846, 720; ${ }^{1} \mathrm{H}-\mathrm{NMR}$ (DMSO- $\left.d_{6}\right): 6.37(1 \mathrm{H}, \mathrm{d}, \mathrm{pym}, \mathrm{J}=7.6), 7.16\left(2 \mathrm{H}, \mathrm{s}, \mathrm{NH}_{2}\right), 7.48(1 \mathrm{H}, \mathrm{dd}, \mathrm{th}, \mathrm{J}=5.2, \mathrm{~J}=1.2), 7.57(1 \mathrm{H}$, $\mathrm{dd}$, th, J=5.2, J=2.6), $7.74(1 \mathrm{H}, \mathrm{s}, \mathrm{im}), 7.80(1 \mathrm{H}, \mathrm{dd}, \mathrm{th}, \mathrm{J}=2.6, \mathrm{~J}=1.2), 8.36(1 \mathrm{H}, \mathrm{d}, \mathrm{pym}, \mathrm{J}=7.6)$. Anal. Calcd for $\mathrm{C}_{10} \mathrm{H}_{8} \mathrm{~N}_{4} \mathrm{~S}$ (MW 216.26): C, 68.90; H, 5.14; N, 4.46. Found: C, 69.04; H, 5.02; N, 4.78 .

\section{Synthesis of 2,8-di(thiophen-3-yl)diimidazo[1,2-a:1',2'-c]pyrimidine (13b) (Scheme 1)}

Compound 12b (5 mmol) was dissolved in ethanol (40 mL), treated with excess of 2-bromo-1(thiophen-3-yl)ethan-1-one $(20 \mathrm{mmol}$ ) and kept under reflux for $7 \mathrm{~h}$. The resulting compound $\mathbf{1 3 b}$ hydrobromide was collected by filtration and treated with $15 \% \mathrm{NH}_{4} \mathrm{OH}$ in order to prepare the free base which was collected by filtration and crystallized from ethanol. Yield $12 \%, \mathrm{mp} 245-249{ }^{\circ} \mathrm{C}$ dec; IR $\left(\mathrm{cm}^{-1}\right): 1635,1292,1193,852,724 ;{ }^{1} \mathrm{H}-\mathrm{NMR}$ (DMSO-d $)$ : $7.16(1 \mathrm{H}, \mathrm{d}, \mathrm{pym}, \mathrm{J}=7.6), 7.56$ $(1 \mathrm{H}$, dd, th, $\mathrm{J}=5.0, \mathrm{~J}=1.2), 7.63(1 \mathrm{H}, \mathrm{dd}, \mathrm{th}, \mathrm{J}=5.0, \mathrm{~J}=3.0), 7.65(1 \mathrm{H}, \mathrm{dd}, \mathrm{th}, \mathrm{J}=5.0, \mathrm{~J}=3.0), 7.75(1 \mathrm{H}$, $\mathrm{dd}$, th, $\mathrm{J}=5.0, \mathrm{~J}=1.2), 7.83(1 \mathrm{H}, \mathrm{dd}, \mathrm{th}, \mathrm{J}=3.0, \mathrm{~J}=1.2), 7.99(1 \mathrm{H}, \mathrm{dd}, \mathrm{th}, \mathrm{J}=3.0, \mathrm{~J}=1.2), 8.09(1 \mathrm{H}, \mathrm{s}$, 
im), $8.28(1 \mathrm{H}, \mathrm{d}, \mathrm{pym}, \mathrm{J}=7.6), 8.61(1 \mathrm{H}, \mathrm{s}, \mathrm{im})$. Anal. Calcd for $\mathrm{C}_{16} \mathrm{H}_{10} \mathrm{~N}_{4} \mathrm{~S}_{2}$ (MW 322.41): C, 59.61; H, 3.13; N, 17.38. Found: C, 60.03; H, 3.67; N, 17.99.

\section{Synthesis of 1,7-dimethyl-5,7-dihydropyrrolo[3,2-f]indole-2,6(1H,3H)-dione (16) (Scheme 2)}

Compound $15(10 \mathrm{mmol})$ was dissolved in toluene $(20 \mathrm{~mL})$ and treated with a solution of $\mathrm{NaOH}$ (20 mmol) in $\mathrm{H}_{2} \mathrm{O}(4 \mathrm{~mL})$. Chloroacetyl chloride $(20 \mathrm{mmol})$ was added dropwise at $0-15^{\circ} \mathrm{C}$. The reaction mixture was kept for $3 \mathrm{~h}$ at room temperature. The aqueous phase was removed and the organic layer was washed with $\mathrm{HCl} 2 \mathrm{~N}$ and with $\mathrm{H}_{2} \mathrm{O}$. Toluene was removed under reduced pressure and the resulting residue was treated with $\mathrm{AlCl}_{3}(10 \mathrm{~g})$ at $160^{\circ} \mathrm{C}$ for $6 \mathrm{~h}$. The mixture was then poured onto ice. The crude compound $\mathbf{1 6}$ was collected by filtration and crystallized from ethanol. Yield 45\%; mp $275{ }^{\circ} \mathrm{C} \mathrm{dec}$; IR $\left(\mathrm{cm}^{-1}\right): 1705,1625,1276,1025,641 ;{ }^{1} \mathrm{H}-\mathrm{NMR}$ (DMSO- $\left.d_{6}\right)$ : $3.14\left(6 \mathrm{H}, \mathrm{s}, \mathrm{CH}_{3}\right), 3.48\left(4 \mathrm{H}, \mathrm{s}, \mathrm{CH}_{2}\right), 6.76(1 \mathrm{H}, \mathrm{s}, \mathrm{ar}), 7.13\left(1 \mathrm{H}, \mathrm{s}\right.$, ar). Anal. Calcd for $\mathrm{C}_{12} \mathrm{H}_{12} \mathrm{~N}_{2} \mathrm{O}_{2}$ (MW 216.24): C, 66.65; H, 5.59; N, 12.96. Found: C, 68.03; H, 6.05; N, 13.11.

\section{General procedure for the synthesis of the aldehydes 14b (Scheme 1) and 17, 20, 21 (Scheme} 2)

The Vilsmeier reagent was prepared at $0-5^{\circ} \mathrm{C}$ by dropping $\mathrm{POCl}_{3}(54 \mathrm{mmol})$ into a stirred solution of DMF (65 mmol) in $\mathrm{CHCl}_{3}(5 \mathrm{~mL})$. The appropriate starting compound (13b, 16, 18, 19, $5 \mathrm{mmol})$ was suspended in $\mathrm{CHCl}_{3}(20 \mathrm{~mL})$. The mixture thus obtained was dropped into the Vilsmeier reagent while maintaining stirring and cooling. The reaction mixture was kept for $3 \mathrm{~h}$ at room temperature and under reflux for 2-40 h (according to a TLC test). Chloroform was removed under reduced pressure, the resulting oil was poured onto ice and the precipitate thus obtained was collected by filtration. The crude aldehydes $\mathbf{1 4 b}$ and 17 were crystallized from ethanol. The aldehydes 20 and 21 were isolated by column chromatography (petroleum ether/acetone, 70/30).

2,8-Di(thiophen-3-yl)diimidazo[1,2-a:1',2'-c]pyrimidine-3,9-dicarbaldehyde (14b). Yield 99\%; mp 242-247 ${ }^{\circ} \mathrm{C} \mathrm{dec}$; IR $\left(\mathrm{cm}^{-1}\right): 1662,1627,1319,866,794 ;{ }^{1} \mathrm{H}-\mathrm{NMR}$ (DMSO-d 6 ): 7.57 (1H, d, pym, 
$\mathrm{J}=7.8), 7.68(1 \mathrm{H}, \mathrm{dd}, \mathrm{th}, \mathrm{J}=5.2, \mathrm{~J}=3.0), 7.80(2 \mathrm{H}, \mathrm{m}, \mathrm{th}), 7.99(1 \mathrm{H}, \mathrm{dd}, \mathrm{th}, \mathrm{J}=5.2, \mathrm{~J}=1.2), 8.44(1 \mathrm{H}$, $\mathrm{dd}, \mathrm{J}=2.4, \mathrm{~J}=1.2), 8.90(1 \mathrm{H}, \mathrm{dd}, \mathrm{th}, \mathrm{J}=3.0, \mathrm{~J}=1.2), 9.21(1 \mathrm{H}, \mathrm{d}, \mathrm{pym}, \mathrm{J}=7.8), 10.25(1 \mathrm{H}, \mathrm{s}, \mathrm{CHO})$, $11.38\left(1 \mathrm{H}, \mathrm{s}, \mathrm{CHO}\right.$ ). Anal. Calcd for $\mathrm{C}_{18} \mathrm{H}_{10} \mathrm{~N}_{4} \mathrm{O}_{2} \mathrm{~S}_{2}$ (MW 378.43): C, 57.13; H, 2.66; N, 14.81 . Found: C, 56.98; H, 2.74: N, 15.01.

2,6-Dichloro-1,7-dimethyl-1,7-dihydropyrrolo[3,2-f]indole-3,5-dicarbaldehyde (17). Yield 85\%; mp $300{ }^{\circ} \mathrm{C} \mathrm{dec}$ IR $\left(\mathrm{cm}^{-1}\right): 1644,1506,1096,1049,718 ;{ }^{1} \mathrm{H}-\mathrm{NMR}\left(\mathrm{CF}_{3} \mathrm{COOD}\right): 4.12\left(6 \mathrm{H}, \mathrm{s}, \mathrm{CH}_{3}\right)$, $7.79(1 \mathrm{H}, \mathrm{s}, \mathrm{ar}), 9.02(1 \mathrm{H}, \mathrm{s}, \mathrm{ar}), 9.82(2 \mathrm{H}, \mathrm{s}, \mathrm{CHO})$. Anal. Calcd for $\mathrm{C}_{14} \mathrm{H}_{10} \mathrm{Cl}_{2} \mathrm{~N}_{2} \mathrm{O}_{2}$ (MW 309.15): C, 54.39; H, 3.26; N, 9.06. Found: C, 56.22; H, 2.99; N, 8.98.

2-Chloro-1-methyl-1H-indole-3,6-dicarbaldehyde (20). Yield 2\%; mp 181-183 ${ }^{\circ} \mathrm{C}$; IR $\left(\mathrm{cm}^{-1}\right)$ : 1700 , 1686, 1646, 1154, 722; ${ }^{1} \mathrm{H}-\mathrm{NMR}\left(\mathrm{DMSO}-d_{6}\right): 3.93\left(3 \mathrm{H}, \mathrm{s}, \mathrm{CH}_{3}\right), 7.83(1 \mathrm{H}$, dd, ind-5, J=8.4, J=1.2), $8.23(1 \mathrm{H}, \mathrm{d}$, ind-4, J=8.4), $8.24(1 \mathrm{H}, \mathrm{d}$, ind-7, $\mathrm{J}=1.2), 10.03(1 \mathrm{H}, \mathrm{s}, \mathrm{CHO}), 10.07(1 \mathrm{H}, \mathrm{s}, \mathrm{CHO})$. Anal. Calcd for $\mathrm{C}_{11} \mathrm{H}_{8} \mathrm{ClNO}_{2}$ (MW 221.64): C, 59.61; H, 3.64; N, 6.32. Found: C, 60.04; H, 3.87; N, 5.98.

2-Chloro-1-phenyl-1H-indole-3,6-dicarbaldehyde (21). Yield 7\%; mp 190-195 ${ }^{\circ} \mathrm{C}$; IR ( $\left.\mathrm{cm}^{-1}\right)$ : 1654 , 1608, 1151, 827, 725; ${ }^{1} \mathrm{H}-\mathrm{NMR}$ (DMSO- $\left.d_{6}\right): 7.66(1 \mathrm{H}, \mathrm{d}$, ind-7, J=1.6), $7.71(5 \mathrm{H}, \mathrm{m}, \mathrm{ph}), 7.89(1 \mathrm{H}$, dd, ind-5, J=8.4, J=1.6), 8.36 (1H, d, ind-4, J=8.4), 10.00 (1H, s, CHO), 10.16 (1H, s, CHO). Anal. Calcd for $\mathrm{C}_{16} \mathrm{H}_{10} \mathrm{ClNO}_{2}$ (MW 283.71): C, 67.74; H, 3.55; N, 4.94. Found: C, 68.02; H, 3.86; N, 5.08

General procedure for the synthesis of the hydrazones 2-5 (Scheme 1) and 6-10 (Scheme 2)

The appropriate aldehyde or ketone $(5 \mathrm{mmol})$ was dissolved in ethanol and treated with two equivalents of :

- 2-hydrazino-2-imidazoline hydrobromide solubilized in ethanol (compounds $\mathbf{2}$ and 3);

- 2-hydrazinopyridine solubilized in ethanol and treated with hydrochloridric acid (compounds 4 and 10); 
- aminoguanidine hydrogencarbonat suspended in ethanol and treated with hydrochloridric acid in order to achieve a solution (compounds 5-9).

The reaction mixture was refluxed for $15-30 \mathrm{~h}$ according to a TLC test and the resulting precipitate was collected by filtration and crystallized from ethanol. Compound $\mathbf{3}$ was obtained as a precipitate from the filtered solution.

3,9-Bis((2-(4,5-dihydro-1H-imidazol-2-yl)hydrazono)methyl)-2,8-diphenyldiimidazo[1,2-a:1',2'-

c]pyrimidine dihydrobromide (2). Yield 22\%; mp $300{ }^{\circ} \mathrm{C}$; IR $\left(\mathrm{cm}^{-1}\right): 3360,1655,1071,938,718$; ${ }^{1} \mathrm{H}-\mathrm{NMR}\left(\mathrm{DMSO}-d_{6}\right): 3.72\left(4 \mathrm{H}, \mathrm{s}, \mathrm{CH}_{2}\right), 3.81\left(4 \mathrm{H}, \mathrm{s}, \mathrm{CH}_{2}\right), 7.37(1 \mathrm{H}, \mathrm{d}, \mathrm{pym}, \mathrm{J}=8.0), 7.49$ (3H, m, ph), $7.58(3 \mathrm{H}, \mathrm{m}, \mathrm{ph}), 7.84(2 \mathrm{H}, \mathrm{d}, \mathrm{ph}, \mathrm{J}=8.2), 8.12(2 \mathrm{H}, \mathrm{d}, \mathrm{ph}, \mathrm{J}=8.2), 8.29$ (2H, broad,

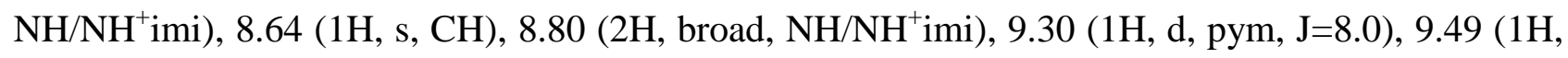
s, CH), $12.50\left(2 \mathrm{H}\right.$, broad, NNH); ${ }^{13} \mathrm{C}-\mathrm{NMR}$ (DMSO-d $): 42.82,42.92,103.69,115.28,117.74$, $128.00,128.38,128.87,128.97,129.07,129.22,129.51,131.80,132.70,139.73,139.77,140.22$, 142.16, 145.73, 146.45, 157.07, 157.68. Anal. Calcd for $\mathrm{C}_{28} \mathrm{H}_{26} \mathrm{~N}_{12} 2 \mathrm{HBr}$ (MW 692.43): C, 48.57; H, 4.08; N, 24.27. Found: C, 48.93; H, 3.95; N, 24.87.

9-((2-(4,5-Dihydro-1H-imidazol-2-yl)hydrazono)methyl)-2,8-diphenyldiimidazo[1,2-a:1',2'-

c]pyrimidine-3-carbaldehyde hydrobromide (3). Yield 50\%; mp $320{ }^{\circ} \mathrm{C}$; IR $\left(\mathrm{cm}^{-1}\right): 3321,1668$, 1625, 774, 699; ${ }^{1} \mathrm{H}-\mathrm{NMR}\left(\mathrm{DMSO}-d_{6}\right): 3.72\left(4 \mathrm{H}, \mathrm{s}, \mathrm{CH}_{2}\right), 7.50(3 \mathrm{H}, \mathrm{m}, \mathrm{ph}), 7.52$ (1H, d, pym, J=7.4), $7.61(3 \mathrm{H}, \mathrm{m}, \mathrm{ph}), 8.03(2 \mathrm{H}, \mathrm{m}, \mathrm{ph}), 8.12$ (2H, m, ph), 8.29 (2H, broad, NH/NH ${ }^{+}$imi $), 9.12$ $\left(1 \mathrm{H}, \mathrm{d}\right.$, pym, J=7.4), $9.47(1 \mathrm{H}, \mathrm{s}, \mathrm{CH}), 10.09(1 \mathrm{H}, \mathrm{s}, \mathrm{CHO}), 12.71\left(1 \mathrm{H}\right.$, broad, NNH); ${ }^{13} \mathrm{C}-\mathrm{NMR}$ (DMSO- $\left.d_{6}\right): 42.93,105.05,117.91,120.24,126.27,128.01,128.95,129.01,129.52,129.63$, 130.17, 131.02, 132.51, 139.92, 140.47, 142.39, 145.94, 152.81, 157.71, 180.42. Anal. Calcd for $\mathrm{C}_{25} \mathrm{H}_{20} \mathrm{~N}_{8} \mathrm{O} \cdot \mathrm{HBr}$ (MW 529.39): C, 56.72; H, 4.00; N, 21.17. Found: C, 57.03; H, 3.89; N, 21.84.

2,8-Diphenyl-3,9-bis((2-(pyridin-2-yl)hydrazono)methyl)diimidazo[1,2-a:1',2'-c]pyrimidine dihydrochloride (4). Yield 71\%; mp 267-270 ${ }^{\circ} \mathrm{C}$; IR $\left(\mathrm{cm}^{-1}\right): 3380,1651,1612,1276,707 ;{ }^{1} \mathrm{H}-\mathrm{NMR}$ (DMSO- $\left.d_{6}\right): 3.75\left(2 \mathrm{H}\right.$, broad, $\mathrm{NH}^{+}$py), $7.00(1 \mathrm{H}, \mathrm{t}, \mathrm{py}, \mathrm{J}=6.0), 7.08(1 \mathrm{H}, \mathrm{t}, \mathrm{ph}, \mathrm{J}=7.2), 7.17(1 \mathrm{H}, \mathrm{d}$, pym, J=8.0), 7.28 (1H, d, py, J=8.4), 7.40 (1H, d, py, J=8.4), 7.43-7.53 (4H, m, 3Hph+1Нpy), 7.56 
(2H, t, ph, J=7.2), 7.93 (2H, d, ph, J=7.2), 7.95 (1H, t, py, J=8.4), 8.06 (1H, t, py, J=8.4), 8.09 (1H, d, py, J=6.0), $8.14(2 \mathrm{H}, \mathrm{d}, \mathrm{ph}, \mathrm{J}=7.2), 8.22(1 \mathrm{H}, \mathrm{d}, \mathrm{py}, \mathrm{J}=6.0), 8.83(1 \mathrm{H}, \mathrm{s}, \mathrm{CH}), 9.56(1 \mathrm{H}, \mathrm{d}, \mathrm{pym}$, $\mathrm{J}=8.0), 9.64(1 \mathrm{H}, \mathrm{s}, \mathrm{CH}), 12.82\left(1 \mathrm{H}\right.$, broad, NNH), $13.13\left(1 \mathrm{H}\right.$, broad, NNH); ${ }^{13} \mathrm{C}-\mathrm{NMR}\left(\mathrm{DMSO}-d_{6}\right)$ : $103.77,111.67,114.60,114.96,115.54,118.87,127.92,128.40,128.69,128.88,129.05,129.09$, 129.32, 131.82, 133.16, 139.67, 141.84, 144.91, 146.08. Anal. Calcd for $\mathrm{C}_{32} \mathrm{H}_{24} \mathrm{~N}_{10} 2 \mathrm{HCl}$ (MW 621.52): C, 61.84; H, 4.22; N, 22.54. Found: C, 62.05; H, 4.59; N, 22.87.

2,2'-((2,8-Di(thiophen-3-yl)diimidazo[1,2-a:1',2'-c]pyrimidine-3,9-

diyl)bis(methanylylidene))bis(hydrazine-1-carboximidamide) dihydrochloride (5). Yield 98\%; mp 265-269 ${ }^{\circ} \mathrm{C} \mathrm{dec}$; IR $\left(\mathrm{cm}^{-1}\right): 3358,1675,1623,1149,866 ;{ }^{1} \mathrm{H}-\mathrm{NMR}$ (DMSO- $\left.d_{6}\right): 7.28$ (1H, d, pym, $\mathrm{J}=8.0), 7.66(1 \mathrm{H}, \mathrm{dd}, \mathrm{th}, \mathrm{J}=5.2, \mathrm{~J}=2.8), 7.69\left(8 \mathrm{H}\right.$, broad, $\left.\mathrm{NH}_{2} / \mathrm{NH}_{2}{ }^{+}\right), 7.76(1 \mathrm{H}, \mathrm{dd}, \mathrm{th}, \mathrm{J}=5.2, \mathrm{~J}=1.2)$, $7.78(1 \mathrm{H}, \mathrm{dd}, \mathrm{th}, \mathrm{J}=5.2, \mathrm{~J}=1.2), 7.81(1 \mathrm{H}, \mathrm{dd}, \mathrm{th}, \mathrm{J}=5.2, \mathrm{~J}=2.8), 8.26(1 \mathrm{H}, \mathrm{dd}, \mathrm{th}, \mathrm{J}=2.8, \mathrm{~J}=1.2), 8.47$ $(1 \mathrm{H}, \mathrm{dd}, \mathrm{th}, \mathrm{J}=2.8, \mathrm{~J}=1.2), 8.82(1 \mathrm{H}, \mathrm{s}, \mathrm{CH}), 9.26(1 \mathrm{H}, \mathrm{d}, \mathrm{pym}, \mathrm{J}=8.0), 9.69(1 \mathrm{H}, \mathrm{s}, \mathrm{CH}), 12.02(1 \mathrm{H}$, s, NNH), $12.57(1 \mathrm{H}, \mathrm{s}, \mathrm{NNH}) ;{ }^{13} \mathrm{C}-\mathrm{NMR}$ (DMSO- $\left.d_{6}\right): 103.26,114.63,117.54,125.72,126.32$, $126.88,127.45,127.77,128.44,128.56,133.95,134.00,138.43,139.19,139.57,141.27,141.77$, 142.05, 154.67, 155.20. Anal. Calcd for $\mathrm{C}_{20} \mathrm{H}_{18} \mathrm{~N}_{12} \mathrm{~S}_{2} 2 \mathrm{HCl}$ (MW 563.49): C, 42.63; H, 3.58; N, 29.83. Found: C, 42.97; H, 3.02; N, 30.05 .

2,2'-((2,6-Dichloro-1,7-dimethyl-1,7-dihydropyrrolo[3,2-f]indole-3,5-

diyl)bis(methanylylidene))bis(hydrazine-1-carboximidamide) dihydrochloride (6). Yield 50\%; mp $350{ }^{\circ} \mathrm{C} \mathrm{dec}$; IR $\left(\mathrm{cm}^{-1}\right): 3329,1643,1516,1148,1096 ;{ }^{1} \mathrm{H}-\mathrm{NMR}$ (DMSO-d $)$ ) $3.88\left(6 \mathrm{H}, \mathrm{s}, \mathrm{CH}_{3}\right), 7.60$ $\left(8 \mathrm{H}\right.$, broad, $\left.\mathrm{NH}_{2} / \mathrm{NH}_{2}{ }^{+}\right), 7.88(1 \mathrm{H}, \mathrm{s}$, ar) $, 8.47(2 \mathrm{H}, \mathrm{s}, \mathrm{CH}), 8.68(1 \mathrm{H}, \mathrm{s}, \mathrm{ar}), 11.70(2 \mathrm{H}$, broad, $\mathrm{NNH}$ ); ${ }^{13} \mathrm{C}-\mathrm{NMR}$ (DMSO-d $)$ : 30.65, 91.84, 105.66, 112.71, 119.67, 130.97, 134.61, 143.06, 154.53. Anal. Calcd for $\mathrm{C}_{16} \mathrm{H}_{18} \mathrm{Cl}_{2} \mathrm{~N}_{10} 2 \mathrm{HCl}$ (MW 494.21): C, 38.89; H, 4.08; N, 28.34. Found: C, $39.03 ; \mathrm{H}, 3.87 ; \mathrm{N}, 28.84$.

2,2'-((2-Chloro-1-methyl-1H-indole-3,6-diyl)bis(methanylylidene))bis(hydrazine-1-

carboximidamide) dihydrochloride (7). Yield 75\%; $\mathrm{mp} \mathrm{235-240}{ }^{\circ} \mathrm{C}$; IR $\left(\mathrm{cm}^{-1}\right): 3150,1670,1605$, 1129, 934; ${ }^{1} \mathrm{H}-\mathrm{NMR}\left(\mathrm{DMSO}-d_{6}\right): 3.85\left(3 \mathrm{H}, \mathrm{s}, \mathrm{CH}_{3}\right), 7.67(1 \mathrm{H}, \mathrm{d}$, ind, $\mathrm{J}=7.8), 7.70(8 \mathrm{H}$, broad, 
$\mathrm{NH}_{2} / \mathrm{NH}_{2}{ }^{+}$gua $), 8.15(1 \mathrm{H}, \mathrm{s}, \mathrm{CH}), 8.30(1 \mathrm{H}, \mathrm{s}, \mathrm{CH}), 8.35(2 \mathrm{H}, \mathrm{d}$, ind, J=7.8), $12.03(1 \mathrm{H}, \mathrm{s}, \mathrm{NNH})$, $12.14(1 \mathrm{H}, \mathrm{s}, \mathrm{NNH}) ;{ }^{13} \mathrm{C}-\mathrm{NMR}\left(\mathrm{DMSO}-d_{6}\right): 30.57,106.59,109.60,121.59,121.95,124.42,128.72$, 131.93, 136.15, 141.62, 147.32, 154.86, 155.44. Anal. Calcd for $\mathrm{C}_{13} \mathrm{H}_{16} \mathrm{ClN}_{9} \cdot 2 \mathrm{HCl}(\mathrm{MW} 406.70)$ : C, 38.39; H, 4.46; N, 31.00. Found: C, 38.78; H, 4.73; N, 29.02.

2,2'-((2-Chloro-1-phenyl-1H-indole-3,6-diyl)bis(methanylylidene))bis(hydrazine-1-

carboximidamide) dihydrochloride (8). Yield 67\%; mp $350{ }^{\circ} \mathrm{C} \mathrm{dec}$; IR $\left(\mathrm{cm}^{-1}\right): 3163,1666,1631$, 1158, 934; ${ }^{1} \mathrm{H}-\mathrm{NMR}\left(\mathrm{DMSO}-d_{6}\right): 7.57$ (5H, m, ph), $7.58(1 \mathrm{H}, \mathrm{d}$, ind-7, J=1.4), 7.76 (8H, broad, $\left.\mathrm{NH}_{2} / \mathrm{NH}_{2}{ }^{+}\right), 7.87(1 \mathrm{H}, \mathrm{dd}$, ind-5, J=8.6, J=1.4), $8.25(1 \mathrm{H}, \mathrm{s}, \mathrm{CH}), 8.47(1 \mathrm{H}, \mathrm{s}, \mathrm{CH}), 8.48(1 \mathrm{H}, \mathrm{d}$, ind4, J=8.6), 12.05 (1H, s, NNH), 12.23 (1H, s, NNH); ${ }^{13}$ C-NMR (DMSO-d $)$ : 108.16, 110.57, 121.45, $122.39,124.54,128.16,129.47,129.55,129.98,131.33,134.31,136.74,141.50,147.71,154.93$, 155.37. Anal. Calcd for $\mathrm{C}_{18} \mathrm{H}_{18} \mathrm{ClN}_{9} \cdot 2 \mathrm{HCl}$ (MW 468.77): C, 46.12; H, 4.30; N, 26.89. Found: C, 45.97; H, 4.78; N, 27.02.

2,2'-(2E-1,1'-Dimethyl-[2,2'-biindolinylidene]-3,3'-diylidene)bis(hydrazine-1-carboximidamide)

dihydrochloride (9). Yield 32\%; mp 315-320 ${ }^{\circ} \mathrm{C}$; IR $\left(\mathrm{cm}^{-1}\right): 3326,1667,1571,1041,722 ;{ }^{1} \mathrm{H}-\mathrm{NMR}$ (DMSO- $\left.d_{6}\right): 3.22\left(6 \mathrm{H}, \mathrm{s}, \mathrm{CH}_{3}\right), 7.16(2 \mathrm{H}, \mathrm{d}$, ind, J=7.6), $7.18(2 \mathrm{H}, \mathrm{t}$, ind, J=7.6), $7.49(2 \mathrm{H}$, t, ind, $\mathrm{J}=7.6), 7.75\left(2 \mathrm{H}, \mathrm{d}\right.$, ind, J=7.6), $8.52\left(8 \mathrm{H}\right.$, broad, $\left.\mathrm{NH}_{2} / \mathrm{NH}_{2}{ }^{+}\right), 12.48(2 \mathrm{H}, \mathrm{s}, \mathrm{NNH}) ;{ }^{13} \mathrm{C}-\mathrm{NMR}$ (DMSO- $\left.d_{6}\right): 25.79,109.94,118.88,121.31,123.00,132.08,136.26,144.09,155.88,160.18$. Anal. Calcd for $\mathrm{C}_{20} \mathrm{H}_{22} \mathrm{~N}_{10} 2 \mathrm{HCl}$ (MW 475.38): C, 50.53; H, 5.09; N, 29.46. Found: C, 50.98; H, 4.86; N, 29.78 .

2E-1,1'-Dimethyl-3,3'-bis(2-(pyridin-2-yl)hydrazono)-2,2'-biindolinylidene dihydrochloride (10). Yield 25\%; mp 255-260 ${ }^{\circ} \mathrm{C}$; IR $\left(\mathrm{cm}^{-1}\right): 3397,1685,1638,1117,1043 ;{ }^{1} \mathrm{H}-\mathrm{NMR}$ (DMSO- $\left.d_{6}\right): 3.26$ $\left(6 \mathrm{H}, \mathrm{s}, \mathrm{CH}_{3}\right), 3.72\left(2 \mathrm{H}\right.$, broad, $\left.\mathrm{NH}^{+} \mathrm{py}\right), 7.16(6 \mathrm{H}, \mathrm{m}, \mathrm{py}), 7.42(2 \mathrm{H}, \mathrm{t}$, ind, J=7.6), $7.67(4 \mathrm{H}, \mathrm{m}$, ind+py), $7.97\left(2 \mathrm{H}, \mathrm{t}\right.$, ind, J=7.6), $8.32\left(2 \mathrm{H}, \mathrm{m}\right.$, ind), $12.84(2 \mathrm{H}, \mathrm{s}, \mathrm{NNH}) ;{ }^{13} \mathrm{C}-\mathrm{NMR}$ (DMSO-d $\left.{ }_{6}\right)$ : $25.58,107.53,109.54,118.60,119.04,119.76,122.65,129.31,129.57,139.17,142.02,147.83$, 154.46, 161.25. Anal. Calcd for $\mathrm{C}_{28} \mathrm{H}_{24} \mathrm{~N}_{8} 2 \mathrm{HCl}$ (MW 545.47): C, 61.65; H, 4.80; N, 20.54. Found: C, 61.20; H, 5.02; N, 20.12. 


\section{Oligonucleotide synthesis and sample preparation}

The DNA sequences were synthesized using standard ß-cyanoethylphosphoramidite solid phase chemistry on an ABI 394 DNA/RNA synthesizer (Applied Biosystem) at the 5- $\mu$ mol scale. DNA detachment from support and deprotection were performed by treatment with concentrated ammonia aqueous solution at $55{ }^{\circ} \mathrm{C}$ for $12 \mathrm{~h}$. The combined filtrates and washings were concentrated under reduced pressure, dissolved in water, and purified by high-performance liquid chromatography (HPLC) on a Nucleogel SAX column (Macherey-Nagel, 1000-8/46), using buffer A consisting of $20 \mathrm{mM} \mathrm{KH} \mathrm{PO}_{4} / \mathrm{K}_{2} \mathrm{HPO}_{4}$ aqueous solution ( $\mathrm{pH} 7.0$ ), containing $20 \%$ (v/v) $\mathrm{CH}_{3} \mathrm{CN}$, buffer $\mathrm{B}$ consisting of $1 \mathrm{M} \mathrm{KCl}, 20 \mathrm{mM} \mathrm{KH} \mathrm{PO}_{4} / \mathrm{K}_{2} \mathrm{HPO}_{4}$ aqueous solution ( $\mathrm{pH}$ 7.0), containing $20 \%(\mathrm{v} / \mathrm{v}) \mathrm{CH}_{3} \mathrm{CN}$, and a linear gradient from $0 \%$ to $100 \% \mathrm{~B}$ for $30 \mathrm{~min}$ with a flow rate $1 \mathrm{~mL} / \mathrm{min}$. The fractions of the oligomers were collected and successively desalted by Sep-pak cartridges (C18). The isolated oligomer was proved to be $>98 \%$ pure by NMR. In particular, the following oligonucleotides have been synthesized: d[TAGGG(TTAGGG) $)_{3}$ (Tel23) and d[(TTAGGG) $)_{4}$ TT] (Tel26) that are two different truncations of human telomeric sequence; two sequences that occur in the nuclease hypersensitive region of the promoter of $c$-KIT oncogene d(AGGGAGGGCGCTGGGAGGAGGG) (c-kit1) and d(CGGGCGGGCGCGAGGGAGGGG) (ckit2); the modified c-kit2 promoter sequence d(CGGGCGGGCGCTAGGGAGGGT) (c-kit2 $2_{\text {T12/T21); }}$ ) the $c-M Y C$ promoter sequence d(TGAGGGTGGGGAGGGTGGGGAAGG) (c-myc); the modified $c-M Y C$ promoter sequence d(TGAGGGTGGGTAGGGTGGGTAA) (Myc22) and the selfcomplementary duplex-forming dodecamer d(CGCGAATTCGCG) (ds12). The concentration of oligonucleotides was determined by UV adsorption measurements at $90{ }^{\circ} \mathrm{C}$ using appropriate molar extinction coefficient values $\varepsilon(\lambda=260 \mathrm{~nm})$ calculated by the nearest neighbour model. ${ }^{35}$ Samples were heated at $90{ }^{\circ} \mathrm{C}$ for $5 \mathrm{~min}$, and then gradually cooled to room temperature overnight. Parallel arrangement of telomeric sequence (Tel23-p) was prepared as previously described. ${ }^{15}$ 


\section{Circular dichroism spectroscopy}

Circular dichroism (CD) experiments were recorded on a Jasco J-815 spectropolarimeter equipped with a PTC-423S/15 Peltier temperature controller. All the spectra were recorded at $20{ }^{\circ} \mathrm{C}$ in the wavelength range of $230-360 \mathrm{~nm}$ and averaged over 3 scans. The scan rate was set to 100 $\mathrm{nm} / \mathrm{min}$, with a $1 \mathrm{~s}$ response time, and $1 \mathrm{~nm}$ bandwidth. Buffer baseline was subtracted from each spectrum. For the CD experiments in presence of metal cations, $10 \mu \mathrm{M}$ G4 DNA and $15 \mu \mathrm{M}$ duplex DNA were used. CD spectra of DNA/ligand mixtures were obtained by adding 4 molar equiv. of ligands (stock solutions of ligands were $6 \mathrm{mM}$ in DMSO). DNAs were prepared in $10 \mathrm{mM}$ potassium phosphate (for c-kit1, Tel23 and Tel26) or $10 \mathrm{mM}$ lithium phosphate (for Tel23-p and ds12) buffers ( $\mathrm{pH} 7.0$ ) containing $100 \mathrm{mM} \mathrm{KCl}$. Because the $\mathrm{T}_{\mathrm{m}}$ value of the c-myc $\mathrm{G} 4$ alone is above $80{ }^{\circ} \mathrm{C}$ in buffer containing $100 \mathrm{mM} \mathrm{KCl}$, it is very difficult to evaluate the stabilizing effects of adding ligands (see Figure S6), thus a buffer solution containing lower amounts of $\mathrm{K}^{+}(5 \mathrm{mM}$ potassium phosphate, $20 \mathrm{mM} \mathrm{KCl}$ ) was used for the experiments on c-myc G4. As for c-kit2, it was shown that this sequence forms a dimeric $\mathrm{G} 4$ in $100 \mathrm{mM} \mathrm{K}^{+}$-containing solution, ${ }^{31}$ with a completely different fold compared to the monomeric G4 that is formed in buffer solution containing low amounts of $\mathrm{K}^{+} \cdot{ }^{31,32}$ Therefore, $5 \mathrm{mM}$ potassium phosphate buffer containing $20 \mathrm{mM}$ $\mathrm{KCl}$ was also used in this case.

For the studies in the absence of metal cations, oligonucleotides $(12-15 \mu \mathrm{M})$ were prepared in 50 $\mathrm{mM}$ Tris buffer, and the CD spectra were recorded $10 \mathrm{~min}$ after each ligand addition (stepwise additions of 0.5 equiv.). All spectra were baseline corrected and analyzed using Origin 7.0 software. CD melting were carried out in the $20-100{ }^{\circ} \mathrm{C}$ temperature range, at $1{ }^{\circ} \mathrm{C} / \mathrm{min}$ heating rate by following changes of $\mathrm{CD}$ signal at the wavelengths of the maximum $\mathrm{CD}$ intensity. $\mathrm{CD}$ melting experiments were recorded in the absence and presence of ligands ( 4 molar equiv.) added to the folded DNA structures. For selected compounds, CD melting experiments were also performed by varying ligand concentration. Three different [ligand]/[DNA] ratio were examined $(1: 1,2: 1$ and 
4:1). The melting temperatures $\left(\mathrm{T}_{\mathrm{m}}\right)$ were determined from curve fit using Origin 7.0 software. $\Delta \mathrm{T}_{\mathrm{m}}$ values were determined as the difference in melting temperature between the G4-DNA with and without ligands.

\section{FRET melting studies}

The ability of the compounds to stabilize DNA sequences was investigated using a fluorescence resonance energy transfer (FRET) assay modified to be used as a high-throughput screen in a 96well format. The studied sequences were the G4 forming sequence 5'-FAM-d(GGG[TTAGGG] $\left.{ }_{3}\right)$ TAMRA-3' $(\mathrm{F} 21 \mathrm{~T}),{ }^{29}$ and the duplex-forming sequence 5'-FAM-dTATAGCTATA-HEGTATAGCTATA-TAMRA-3' (T-loop) (HEG linker: $\left.\quad\left[\left(-\mathrm{CH}_{2}-\mathrm{CH}_{2}-\mathrm{O}-\right)_{6}\right]\right) . \quad$ The labelled oligonucleotides had attached to them the donor fluorophore FAM: 6-carboxyfluorescein and the acceptor fluorophore TAMRA: 6-carboxytetramethylrhodamine. The FRET probe sequences were diluted from stock to the correct concentration $(400 \mathrm{nM})$ in a $60 \mathrm{mM}$ potassium cacodylate buffer $\left(\mathrm{pH}\right.$ 7.4) and then annealed by heating to $85{ }^{\circ} \mathrm{C}$ for $10 \mathrm{~min}$, followed by cooling to room temperature in the heating block. The compounds were stored as a $10 \mathrm{mM}$ stock solution in DMSO; final solutions (at $2 \times$ concentration) were prepared using $10 \mathrm{mM} \mathrm{HCl}$ in the initial 1:10 dilution, after which $60 \mathrm{mM}$ potassium cacodylate buffer ( $\mathrm{pH}$ 7.4) was used in all subsequent steps. The maximum $\mathrm{HCl}$ concentration in the reaction volume (at a ligand concentration of $20 \mu \mathrm{M}$ ) is thus $200 \mu \mathrm{M}$, well within the range of the buffer used. Relevant controls were also performed to check for interference with the assay. 96-Well plates (MJ Research, Waltham, MA) were prepared by aliquoting $50 \mu \mathrm{l}$ of the annealed DNA into each well, followed by $50 \mu 1$ of the compound solutions. Measurements were made on a DNA Opticon Engine (MJ Research) with excitation at 450-495 nm and detection at 515-545 $\mathrm{nm}$. Fluorescence readings were taken at intervals of $0.5^{\circ} \mathrm{C}$ in the range $30-100{ }^{\circ} \mathrm{C}$, with a constant temperature being maintained for $30 \mathrm{~s}$ prior to each reading to ensure a stable value. Final analysis of the data was carried out using a script written in the program Origin 7.0 (OriginLab Corp., Northampton, MA). The advanced curve-fitting function in Origin 7.0 was 
used for calculation of $\Delta \mathrm{T}_{\mathrm{m}}$ values. All determinations were performed in triplicate. Esds in $\Delta \mathrm{T}_{\mathrm{m}}$ are $\pm 0.2{ }^{\circ} \mathrm{C}$.

For selected compounds, additional FRET melting studies were performed by using the following G4 forming sequences: the 5'-FAM-d(GGGCGGGCGCGAGGGAGGGG)-TAMRA-3' (Fckit2T) and 5'-FAM-d(TGAGGGTGGGTAGGGTGGGTAA)-TAMRA-3' (FcmycT) oligonucleotides from the $c-K I T$ and $c-M Y C$ promoter regions, respectively; and the telomeric F21T G4-forming sequence were annealed at high concentrations to promote the parallel conformation (F21T-p). Labeled oligonucleotides were purchased from Biomers (Germany), purified employing standard HPLC protocols. Such studies were performed under the same buffer and experimental conditions used for the corresponding CD experiments. The FRET melting assay was carried out on a FP-8300 spectrofluorometer (Jasco) equipped with a Peltier temperature controller accessory (Jasco PCT818) with excitation at $492 \mathrm{~nm}$ and detection at $522 \mathrm{~nm}$. Both excitation and emission slit widths were set at $5 \mathrm{~nm}$. A sealed quartz cuvette with a path length of $1 \mathrm{~cm}$ was used. The final concentration of the G4s was $0.2 \mu \mathrm{M}$. The fluorescence melting of the G4s was monitored at 1 ${ }^{\circ} \mathrm{C} / \mathrm{min}$ with and without ligands (at a 4:1 ligand/DNA ratio). Final analysis of the data was carried out using Origin 7.0.

\section{Nuclear magnetic resonance experiments}

NMR experiments were performed on a $700 \mathrm{MHz}$ Varian Unity INOVA spectrometer, with data recorded at $25{ }^{\circ} \mathrm{C}$. One-dimensional proton spectra of the sample in $\mathrm{H}_{2} \mathrm{O}$ were recorded using pulsed-field gradient DPFGSE for $\mathrm{H}_{2} \mathrm{O}$ suppression. DNA samples were prepared at 0.2-0.5 mM strand concentration in $0.6 \mathrm{~mL}\left(\mathrm{H}_{2} \mathrm{O} / \mathrm{D}_{2} \mathrm{O}\right.$ 9:1) buffer solution. NMR experiments on $\mathrm{G} 4$ forming oligonucleotides from $c$-MYC (Myc22) and $c$-KIT (c-kit2 ${ }_{\mathrm{T} 12 / \mathrm{T} 21}$ ) promoters were performed employing the same buffers and experimental conditions as used for the determination of their 3D structures, ${ }^{30,31}$ in order to avoid different G4 folds or conformational heterogeneity in solution, which is detrimental to such experiments. The solution was either $25 \mathrm{mM} \mathrm{KH}_{2} \mathrm{PO}_{4}, 70 \mathrm{mM} \mathrm{KCl}$, 0.2 mM EDTA, pH 7.0 (for Myc22) or $5 \mathrm{mM} \mathrm{KH}_{2} \mathrm{PO}_{4}, 20 \mathrm{mM} \mathrm{KCl}, 0.2 \mathrm{mM}$ EDTA, pH 6.8 (for c- 
kit $\left.2_{\mathrm{T} 12 / \mathrm{T} 21}\right)$. Aliquots of a stock solution of $\mathbf{3}$ in DMSO-d6 were added directly to the DNA solution inside the NMR tube. The NMR data were processed on an iMAC running iNMR software (www.inmr.net).

\section{Docking simulations}

The solution structures of G4 formed by the human c-kit2 promoter sequence (PDB ID: $2 \mathrm{KQH}),{ }^{32}$ and of c-myc G4 bound to quindoline molecule (PDB ID: 2L7V) ${ }^{33}$ were used as the targets for docking studies. The ligand found in the c-myc complex was removed from the structure to leave empty binding sites. After optimizing the ligand and assigning partial atomic charges, docking calculations were performed with the AutoDock 4.2 program using the Lamarckian genetic algorithm. ${ }^{36}$ The all parallel-stranded arrangement with propeller loops linking adjacent parallel strands on opposite surfaces of the G4s, results in accessible outer planar G-tetrad surfaces that, being the potential binding sites for the ligands, were defined as the grid boxes for the docking. The size of the boxes was constrained to $18 \AA \times 18 \AA \times 18 \AA$ in the $\mathrm{x}, \mathrm{y}$ and $\mathrm{z}$ dimensions. Grid maps were generated for each atom type in the ligand using AutoGrid. An active site box was created with a grid spacing of $0.375 \AA$. The maximum number of energy evaluations was set to $2.5 \times 10^{6}$, the maximum number of genetic algorithm operations was set to $2.7 \times 10^{4}$, the number of individuals in a population was set to be 300 , the rates of mutation and crossover were set to 0.02 and 0.8 , respectively. When searching the conformational and orientation spaces of ligand with rotatable bonds having full flexibility, the structure of the G4 was kept rigid. The most favorable binding poses were selected on the basis of both the calculated energies and visual inspection. All the figures were drawn using VMD 1.9 software (www.ks.uiuc.edu/Research/vmd). 


\section{Cell cultures and immunofluorescence}

Human osteosarcoma U2OS and colon cancer HCT116 cells were cultured in Dulbecco's Modified Eagle Medium (DMEM) (Carlo Erba), supplemented with 1\% L-glutamine and 10\% FBS (fetal bovine serum). U2OS cells were seeded in $35 \mathrm{~mm}$ dishes at a concentration of 100000 cell $/ \mathrm{ml}$. $24 \mathrm{~h}$ after seeding, cells were treated with $\mathbf{1}(2 \mu \mathrm{M}$ and $10 \mu \mathrm{M}), \mathbf{3}(0.2 \mu \mathrm{M}$ and $1 \mu \mathrm{M})$, or $\mathbf{1 4 a}(2 \mu \mathrm{M}$ and $10 \mu \mathrm{M})$. Cells were then fixed in methanol:acetic acid (3:1), permeabilized with $0.1 \%$ tritonX100/PBS and blocking in 2\% milk/PBS. Immunofluorescence was performed using standard methods with BG4, anti-FLAG (Cell Signaling Technology) and anti-rabbit Alexa 488-conjugated (Invitrogen) antibodies. Nuclei were stained with DAPI (Sigma Aldrich) and coverslips were mounted with Mowiol® 4-88 (Sigma Aldrich). Fluorescence signal was determined using ImageJ software with the following formula: Corrected Total Cell Fluorescence $(\mathrm{CTCF})=$ Integrate Density - (Area of selected cell x Mean Fluorescence of Background Readings). Significance was determined by parametric tests "Student's $t$ test". BG4 antibody was obtained by transfection of BG4 plasmid (kindly obtained by S. Balasubramanian) in BL21 E. coli cells. Then, BG4 protein expression was induced by the autoinduction method as described by Studier. ${ }^{37}$ BG4 was purified by using silica-based resin (Protino ${ }^{\circledR} \mathrm{Ni}-\mathrm{IDA}$ ) pre-charged with $\mathrm{Ni}^{2+}$ ions, eluted with $250 \mathrm{mM}$ Imidazole/PBS pH 8.0. The eluted antibody was concentrated with Amicon Ultra-15 Centrifugal Filter Units (Millipore), and imidazole was finally removed by buffer exchange with PBS pH 8.0 with Amicon Ultra-15 Centrifugal Filter Units.

\section{MTT cell proliferation assay}

U2OS and HCT116 cells were cultured in DMEM as above, and were seeded in 24-well at a concentration of $40000 \mathrm{cell} / \mathrm{ml}$. $24 \mathrm{~h}$ after seeding, cells were treated with the compound at the indicated concentration and time. After $1 \mathrm{~h}$ or $24 \mathrm{~h}$ of treatment, agents were removed and cells were further cultured in complete drug-free medium for 1-2 days. Then, thiazolyl blue tetrazolium bromide (MTT) (Sigma Aldrich) was added to each well and incubated for $1 \mathrm{~h}$ at $37^{\circ} \mathrm{C}$. Then, 
medium was removed and $300 \mu 1$ of dimethyl sulfoxide (Sigma Aldrich) was added and incubated for $1 \mathrm{~h}$ at room temperature. Then, $100 \mu \mathrm{l}$ of the solution was put in 96-well and absorbance at 595 $\mathrm{nm}$ was measured using a multiplate reader. The linear regression parameters were determined to calculate the $\mathrm{IC}_{50}$ (GraphPad Prism 4.0, Graph Pad Software Inc.). 


\section{ASSOCIATED CONTENT}

Supporting Information. CD spectra and CD melting curves of the investigated DNAs in the absence and in presence of 4 molar equiv. of compounds 1-10. FRET-melting experiments at various concentrations of compounds 1-10. CD spectra of labeled oligonucleotides. Additional FRET-melting experiments on compounds 2, 3 and 5. CD titration of the investigated G4s with compounds 2,3 and 4 .

\section{AUTHOR INFORMATION}

\section{Corresponding Author}

*E-mail: antonio.randazzo@ unina.it. Phone: (+39) 081678514.

\section{Author Contributions}

\#J.A. and R.M. contributed equally.

\section{Notes}

The authors declare no competing financial interest.

\section{ACKNOWLEDGMENT}

This work was supported by the Italian Association for Cancer Research (AIRC) (IG-14150 to A.R., IG-16730 to B.P., and IG-15886 to G.C.), by Italian Institute of Technology (IIT), and by “Programma STAR" 2014 of University of Naples "Federico II" to B.P. (n. 14-CSP3-C03-141).

\footnotetext{
ABBREVIATIONS

G4, G-quadruplex; ALT, alternative lengthening of telomere; DMEM, Dulbecco's modified eagle medium; FBS, fetal bovine serum.
} 


\section{REFERENCES}

(1) Bacolla, A.; Wells, R. D. Non-B DNA conformations as determinants of mutagenesis and human disease. Mol. Carcinog. 2009, 48, 273-285.

(2) Balasubramanian, S.; Hurley, L. H.; Neidle, S. Targeting G-quadruplexes in gene promoters: a novel anticancer strategy? Nat. Rev. Drug Discovery 2011, 10, 261-275.

(3) Amato, J.; Iaccarino, N.; Randazzo, A.; Novellino, E.; Pagano, B. Noncanonical DNA secondary structures as drug targets: The prospect of the i-motif. ChemMedChem 2014, 9, 20262030.

(4) Balasubramanian, S.; Neidle, S. G-quadruplex nucleic acids as therapeutic targets. Curr. Opin. Chem. Biol. 2009, 13, 345-353.

(5) Collie, G.; Parkinson, G. The application of DNA and RNA G-quadruplexes to therapeutic medicines. Chem. Soc. Rev. 2011, 40, 5867-5892.

(6) Collado, M.; Blasco, M. A.; Serrano, M. Cellular Senescence in cancer and aging. Cell 2007, 130, 223-233.

(7) Kim, N. W. Clinical implications of telomerase in cancer. Eur. J. Cancer Part A 1997, 33, $781-786$.

(8) Shay, J. W.; Reddel, R. R.; Wright, W. E. Cancer and telomeres - an ALTernative to telomerase. Science 2012, 336, 1388-1390.

(9) Zahler, A. M.; Williamson, J. R.; Cech, T. R.; Prescott, D. M. Inhibition of telomerase by Gquartet DNA structures. Nature 1991, 350, 718-720.

(10) Neidle, S. Human telomeric G-quadruplex: The current status of telomeric G-quadruplexes as therapeutic targets in human cancer. FEBS J. 2010, 277, 1118-1125.

(11) Monchaud, D.; Teulade-Fichou, M. -P. A hitchhiker's guide to G-quadruplex ligands. Org. Biomol. Chem. 2008, 6, 627-636.

(12) Ohnmacht, S. A.; Neidle, S. Small-molecule quadruplex-targeted drug discovery. Bioorg. Med. Chem. Lett. 2014, 24, 2602-2612. 
(13) Cosconati, S.; Rizzo, A.; Trotta, R.; Pagano, B.; Iachettini, S.; De Tito, S.; Lauri, I.; Fotticchia, I.; Giustiniano, M.; Marinelli, L.; Giancola, C.; Novellino, E.; Biroccio, A.; Randazzo, A. Shooting for selective druglike G-quadruplex binders: Evidence for telomeric DNA damage and tumor cell death. J. Med. Chem. 2012, 55, 9785-9792.

(14) Di Leva, F. S.; Zizza, P.; Cingolani, C.; D'Angelo, C.; Pagano, B.; Amato, J.; Salvati, E.; Sissi, C.; Pinato, O.; Marinelli, L.; Cavalli, A.; Cosconati, S.; Novellino, E.; Randazzo, A.; Biroccio, A. Exploring the chemical space of G-quadruplex binders: Discovery of a novel chemotype targeting the human telomeric sequence. J. Med. Chem. 2013, 56, 9646-9654.

(15) Pagano, B.; Amato, J.; Iaccarino, N.; Cingolani, C.; Zizza, P.; Biroccio, A.; Novellino, E.; Randazzo, A. Looking for efficient G-quadruplex ligands: Evidence for selective stabilizing properties and telomere damage by drug-like molecules. ChemMedChem 2015, 10, 640-649.

(16) Sparapani, S.; Bellini, S.; Gunaratnam, M.; Haider, S. M.; Andreani, A.; Rambaldi, M.; Locatelli, A.; Morigi, R.; Granaiola, M.; Varoli, L.; Burnelli, S.; Leoni, A.; Neidle, S. Bisguanylhydrazone diimidazo[1,2-a:1,2-c]pyrimidine as a novel and specific G-quadruplex binding motif. Chem. Commun. 2010, 46, 5680-5682.

(17) Andreani, A.; Granaiola, M.; Leoni, A.; Locatelli, A.; Morigi, R.; Rambaldi, M.; Giorgi, G.; Garaliene, V. Potential antitumor agents. 34. Synthesis and antitumor activity of guanylhydrazones from imidazo[2,1-b]thiazoles and from diimidazo[1,2-a:1,2-c]pyrimidine. Anticancer Res. 2004, 24, 203-212.

(18) Andreani, A.; Rambaldi, M.; Locatelli, A.; Bossa, R.; Fraccari, A.; Galatulas, I. Potential antitumor agents. 21. Structure determination and antitumor activity of imidazo[2,1-b]thiazole guanylhydrazones. J. Med. Chem. 1992, 35, 4634-4637.

(19) Andreani, A.; Granaiola, M.; Leoni, A.; Locatelli, A.; Morigi, R.; Rambaldi, M.; Giorgi, G.; Salvini, L. Cancer fighting cancer: synthesis of the new heterocyclic system diimidazo-[1,2-a:1,2c]-pyrimidine. ARKIVOC 2002, Part XI, 32-38. 
(20) Kipnis, F.; Soloway, H.; Ornfelt, J. 2-Acyloxyacetylthiophenes. J. Am. Chem. Soc. 1949, 71, $10-11$.

(21) Daszkiewicz, Z.; Domanski, A.; Kyziol, J. B. A simple route to N-methylarylamines. Chem. Pap. 1993, 47, 109-113.

(22) Hodges, R.; Shannon, J. S.; Jamieson, W. D.; Taylor, A. Chemical and biological properties of some oxindol-3-ylidene methines. Can. J. Chem. 1968, 46, 2189-2194.

(23) Kisteneva, M. S. Azomethine dyes from oxindole derivatives. Zh. Obshch. Khim. 1956, 26, $1169-1175$.

(24) Russell, G. A.; Kaupp, G. Reactions of resonance stabilized carbanions. XXXI. Oxidation of carbanions. 4. Oxidation of indoxyl to indigo in basic solution. J. Am. Chem. Soc. 1969, 91, 38513859.

(25) Dai, J.; Carver, M.; Yang, D. Polymorphism of human telomeric quadruplex structures. Biochimie 2008, 90, 1172-1183.

(26) Parkinson, G. N.; Lee, M. P.; Neidle, S. Crystal structure of parallel quadruplexes from human telomeric DNA. Nature 2002, 417, 876-880.

(27) Xue, Y.; Kan, Z. Y.; Wang, Q.; Yao, Y.; Liu, J.; Hao, Y. H.; Tan, Z. Human telomeric DNA forms parallel-stranded intramolecular G-quadruplex in $\mathrm{K}+$ solution under molecular crowding condition. J. Am. Chem. Soc. 2007, 129, 11185-11191.

(28) (a) Masiero, S.; Trotta, R.; Pieraccini, S.; De Tito, S.; Perone, R.; Randazzo, A.; Spada, G. P. A non-empirical chromophoric interpretation of CD spectra of DNA G-quadruplex structures. Org. Biomol. Chem. 2010, 8, 2683-2692. (b) Karsisiotis, A. I.; Hessari, N. M.; Novellino, E.; Spada, G. P.; Randazzo, A.; Webba Da Silva, M. Topological characterization of nucleic acid Gquadruplexes by UV absorption and circular dichroism. Angew. Chem. Int. Ed. 2011, 50, 1064510648. (c) Randazzo, A.; Spada, G. P.; Webba Da Silva, M. Circular dichroism of quadruplex structures. Top. Curr. Chem. 2013, 330, 67-86. 
(29) Mergny, J. L.; Maurizot, J. C. Fluorescence resonance energy transfer as a probe for Gquartet formation by a telomeric repeat. ChemBioChem 2001, 2, 124-132.

(30) Ambrus, A.; Chen, D.; Dai, J.; Jones, R. A.; Yang, D. Solution structure of the biologically relevant G-quadruplex element in the human c-MYC promoter. Implications for G-quadruplex stabilization. Biochemistry 2005, 44, 2048-2058.

(31) Kuryavyi, V.; Phan, A. T.; Patel, D. J. Solution structures of all parallel-stranded monomeric and dimeric G-quadruplex scaffolds of the human c-kit2 promoter. Nucleic Acids Res. 2010, 38, $6757-6773$.

(32) Hsu, S. T. D.; Varnai, P.; Bugaut, A.; Reszka, A. P.; Neidle, S.; Balasubramanian, S. A Grich sequence within the c-kit oncogene promoter forms a parallel G-quadruplex having asymmetric G-tetrad dynamics. J. Am. Chem. Soc. 2009, 131, 13399-13409.

(33) Dai, J.; Carver, M.; Hurley, L. H.; Yang, D. Solution structure of a 2:1 quindoline-c-MYC G-quadruplex: Insights into G-quadruplex-interactive small molecule drug design. J. Am. Chem. Soc. 2011, 133, 17673-17680.

(34) Biffi, G.; Tannahill, D.; McCafferty, J.; Balasubramanian, S. Quantitative visualization of DNA G-quadruplex structures in human cells. Nat. Chem. 2013, 5, 182-186.

(35) Cantor, C. R.; Warshaw, M. M.; Shapiro, H. Oligonucleotide interactions. III. Circular dichroism studies of the conformation of deoxyoligonucleolides. Biopolymers 1970, 9, 1059-1077.

(36) Morris, G. M.; Huey, R.; Lindstrom, W.; Sanner, M. F.; Belew, R. K.; Goodsell, D. S.; Olson, A. J. AutoDock4 and AutoDockTools4: Automated docking with selective receptor flexibility. J. Comput. Chem. 2009, 30, 2785-2791.

(37) Studier, F. W. Protein production by auto-induction in high density shaking cultures. Protein Expression Purif. 2005, 41, 207-234. 


\section{FIGURES}
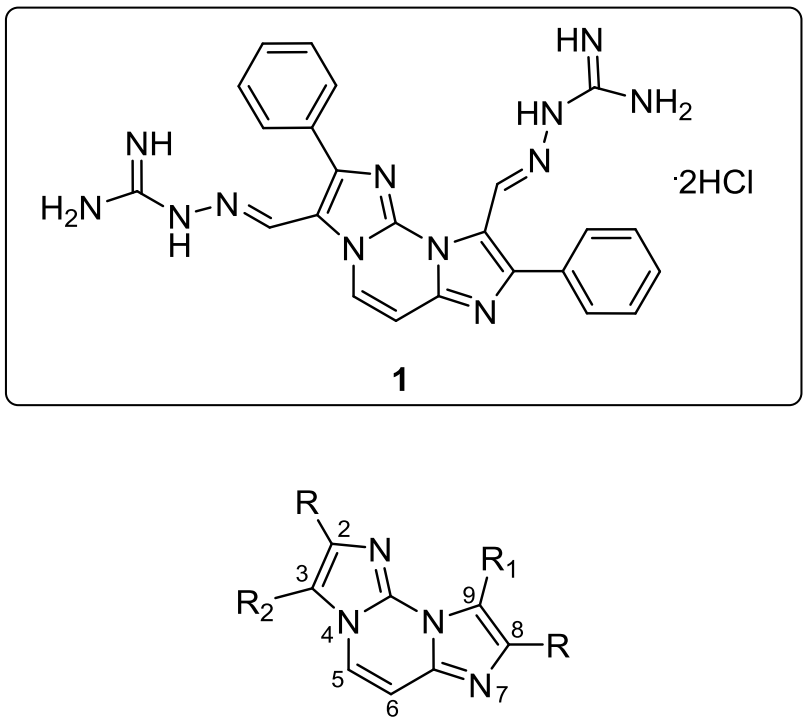

$2 \mathrm{R}=\longrightarrow \mathrm{R}_{1}=\mathrm{R}_{2}=\widehat{\mathrm{N}}^{-\mathrm{N}} \underset{\mathrm{HN}}{\mathrm{N}} \mathrm{N} \cdot \mathrm{HBr}$

$\left.3 \mathrm{R}=\longrightarrow \mathrm{R}_{1}=\mathrm{N}^{-\mathrm{N}} \underset{\mathrm{HN}}{\mathrm{N}}\right\rangle \cdot \mathrm{HBr} \quad \mathrm{R}_{2}=\mathrm{CHO}$

$4 \mathrm{R}=\longrightarrow \mathrm{R}_{1}=\mathrm{R}_{2}=\overbrace{\mathrm{N}^{-}}^{\mathrm{N}} \mathrm{HCl}$

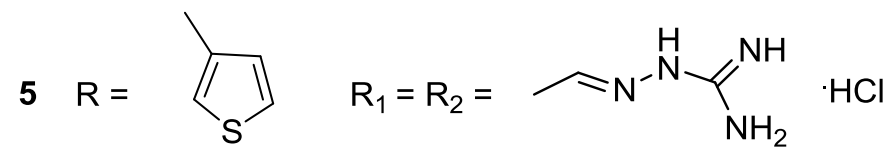<smiles>Cn1c(Cl)c(/C=N/NC(=N)N)c2cc3c(/C=N/NC(=N)N)c(Cl)n(C)c3cc21</smiles><smiles>[R]n1c(Cl)c(/C=N/NC(=N)N)c2ccc(/C=N/NC(=N)N)cc21</smiles>

$7 \quad \mathrm{R}=\mathrm{CH}_{3}$
8

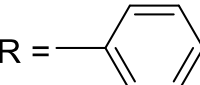<smiles>[R]NN=C1C(=C2C(=N)c3ccccc3N2C)N(C)c2ccccc21</smiles>

$\mathrm{NH}$<smiles>[R]=C(N)[NH3+]</smiles>

Figure 1. Compound lead $\mathbf{1}$ and structural modifications. 

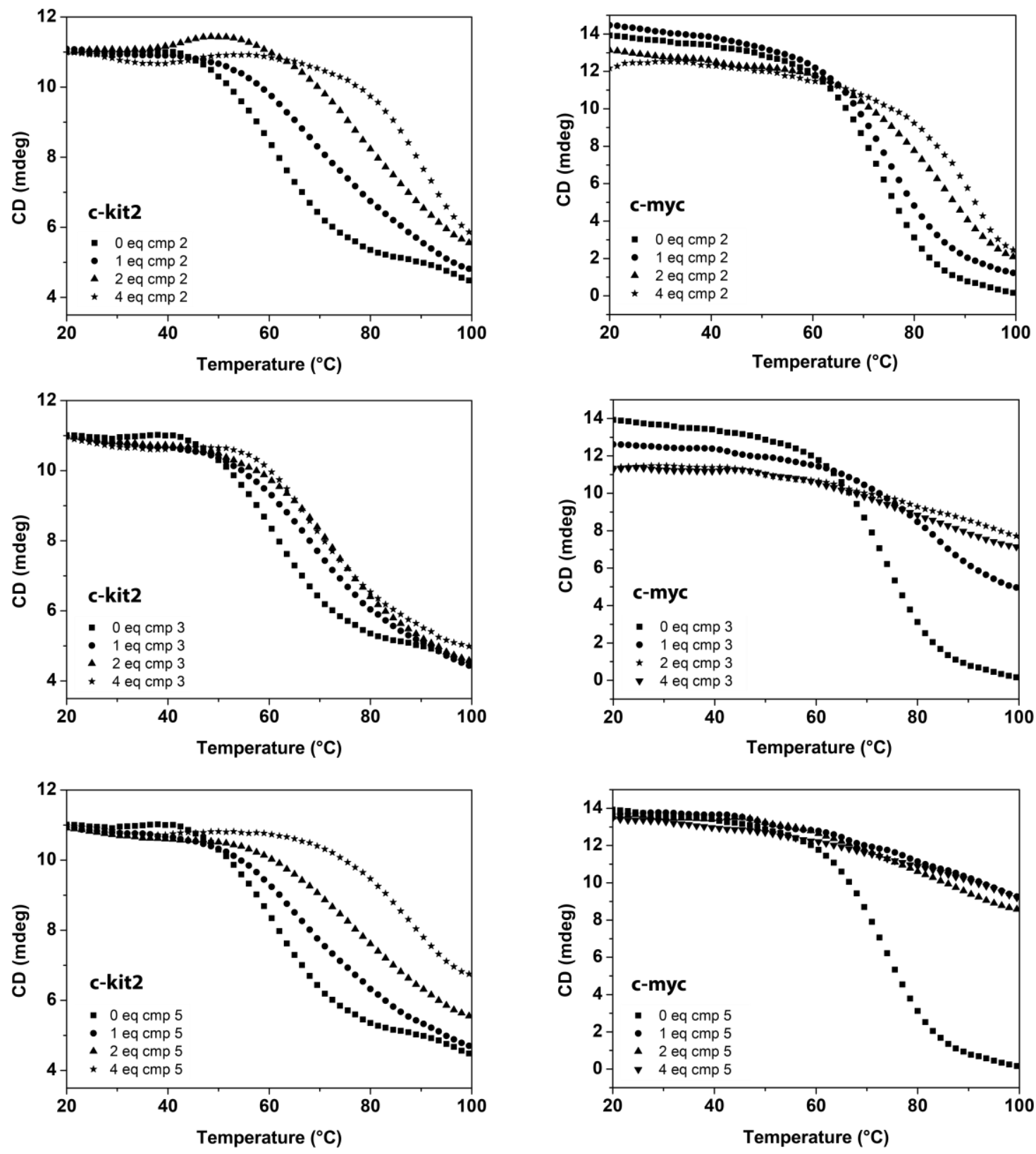

Figure 2. CD melting experiments of c-kit2 (left column) and c-myc (right column) G4s with increasing amounts of compounds $\mathbf{2}, \mathbf{3}$ and $\mathbf{5}$. 

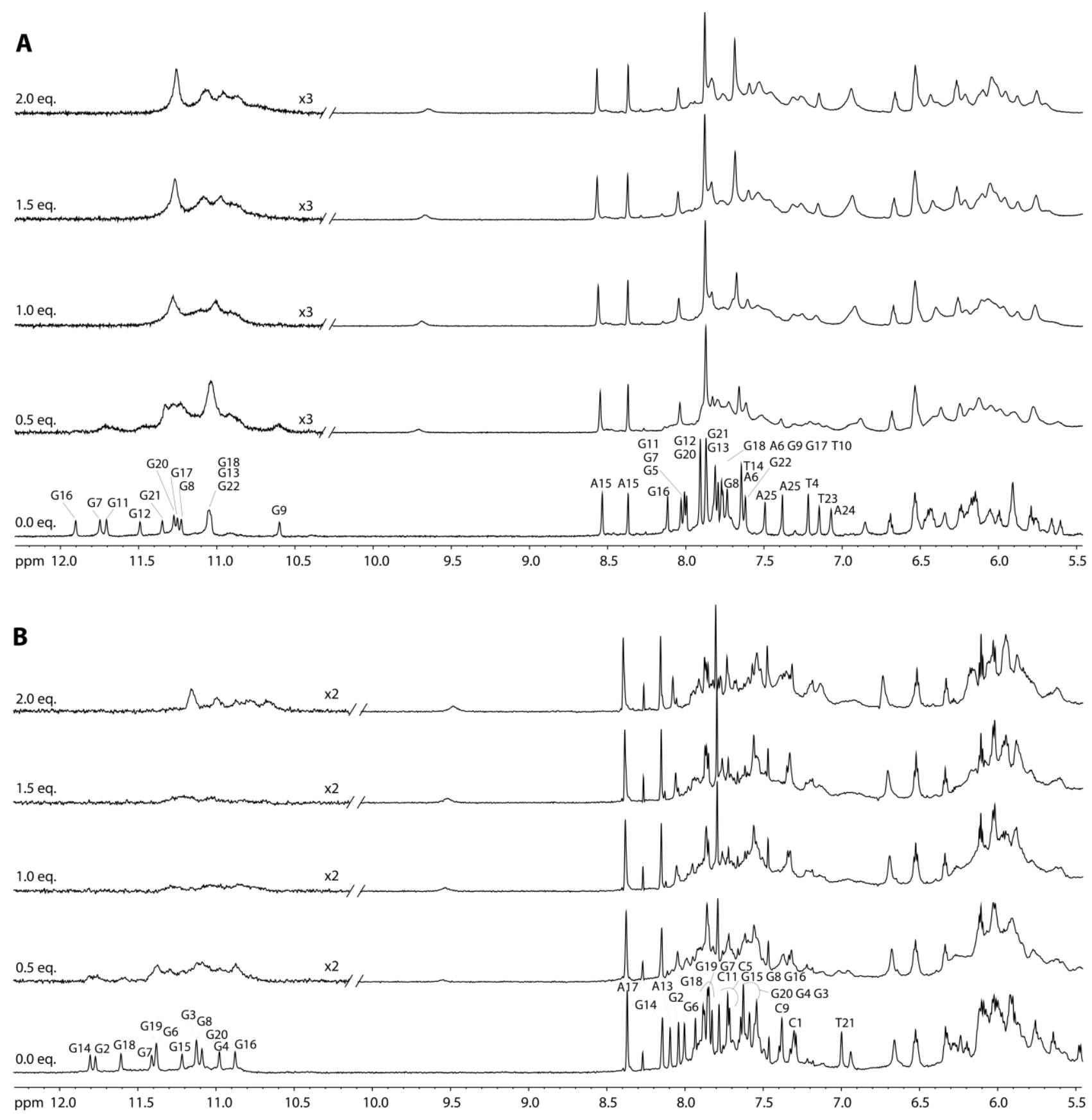

Figure 3. Imino and aromatic proton regions of (A) $c-M Y C$ promoter $\mathrm{G} 4$ (Myc22) in $25 \mathrm{mM}$

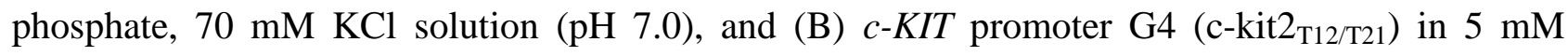
phosphate, $20 \mathrm{mM} \mathrm{KCl}$ solution ( $\mathrm{pH}$ 6.8) titrated with compound $\mathbf{3}$. 


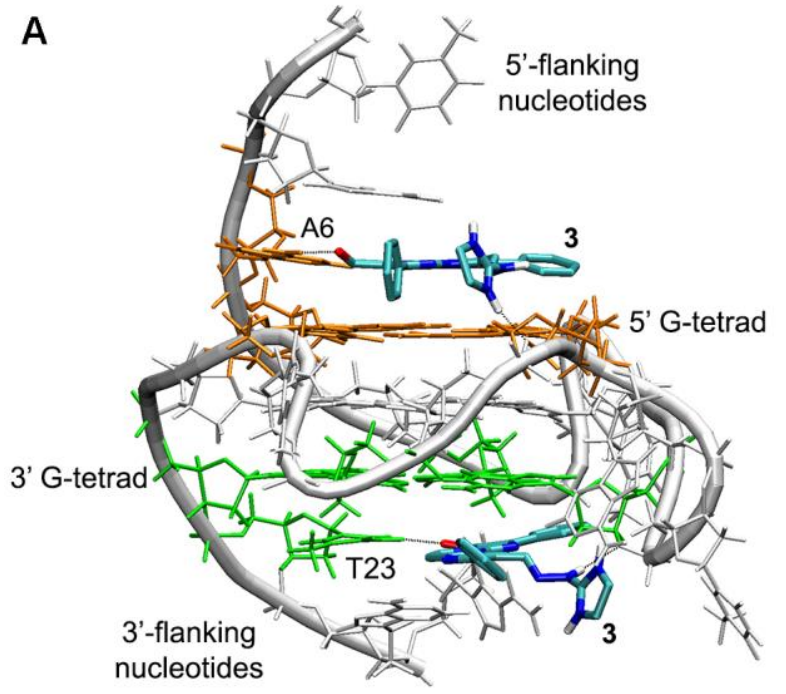

B

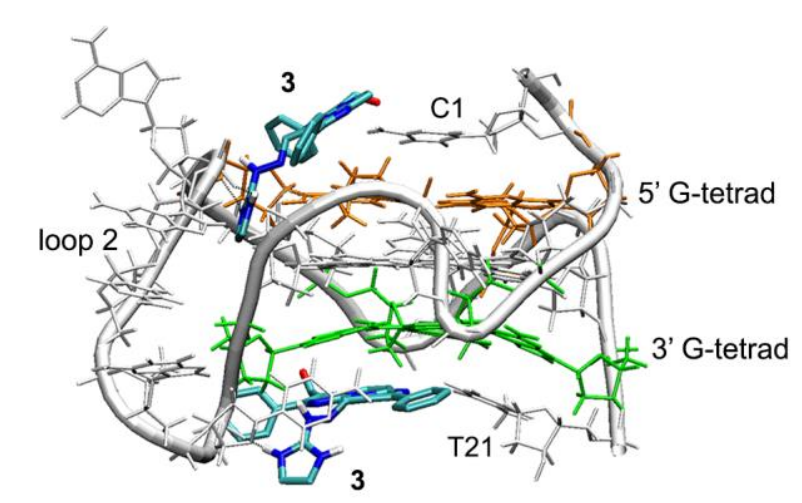

Figure 4. Predicted binding poses upon docking of compound 3 onto the (A) c-myc and (B) c-kit2 G4s. Ligand molecules are represented as sticks. The phosphate backbone and nucleosides of G4s are represented in tube and stick representations, respectively. Black dashed lines indicate hydrogen bond interactions. 
A
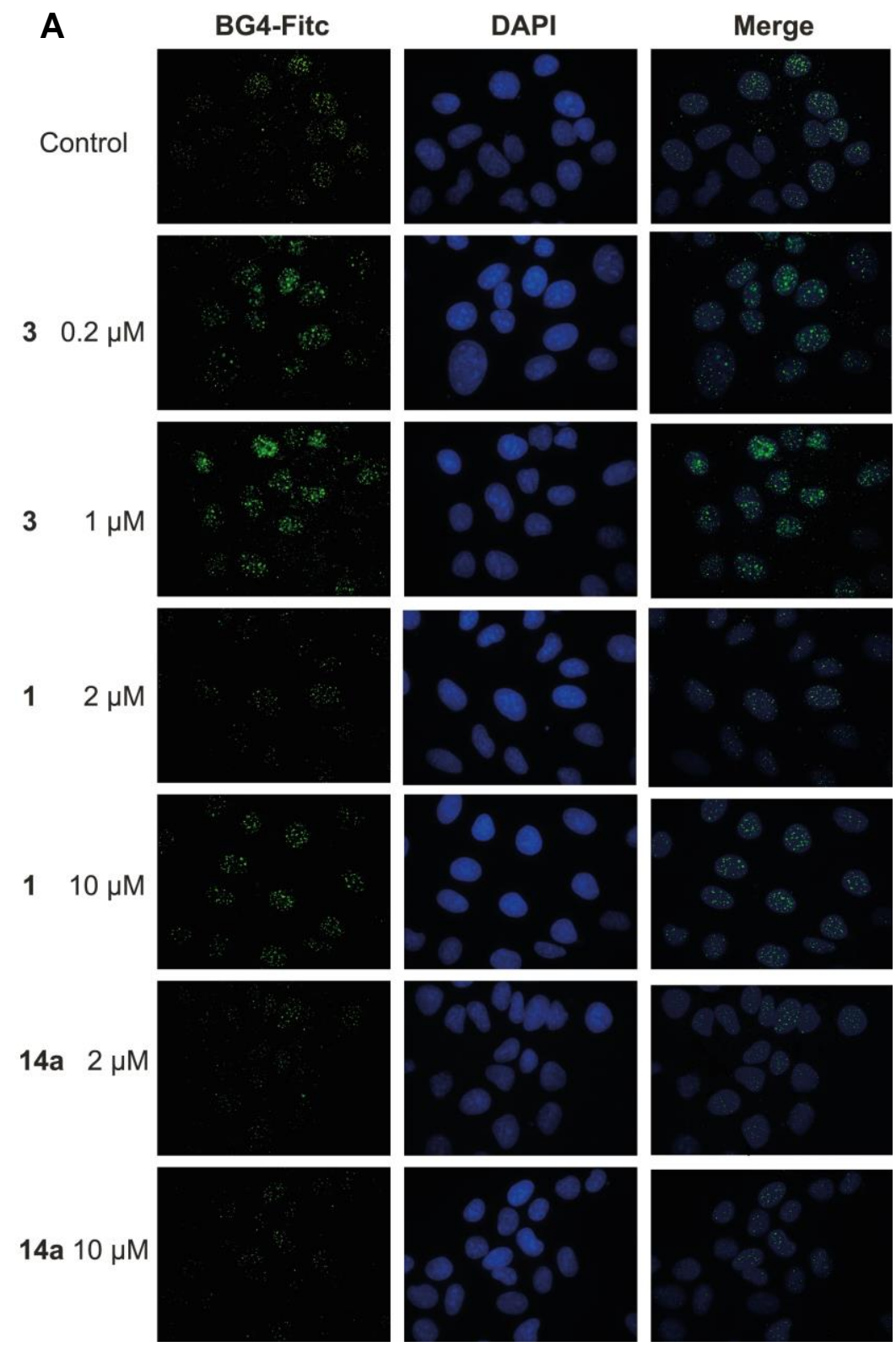

B

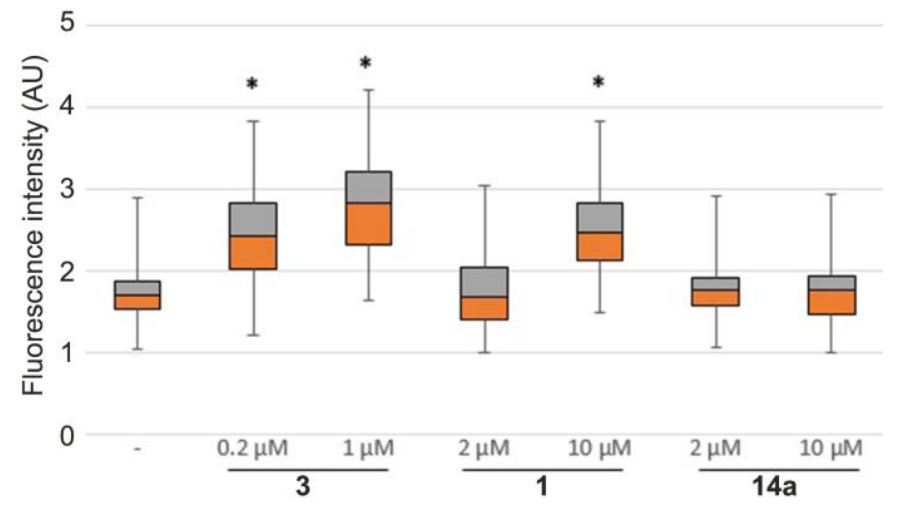

Figure 5. (A) Immunofluorescence showing BG4 foci (green) in human osteosarcoma U2OS cell nuclei (blue). Cells were treated with G4 ligands for $24 \mathrm{~h}$ and then fixed. G4s and DNA were stained with BG4 antibody and DAPI, respectively. (B) Box Plot analysis of G4 signal in the nucleus of control and treated cells. At least two experiments were considered and 150 nuclei were counted per sample. Statistical significance was determined with the $t$ test, and $*$ indicates a $p$ value less than $10^{-32}$. 


\section{SCHEMES}

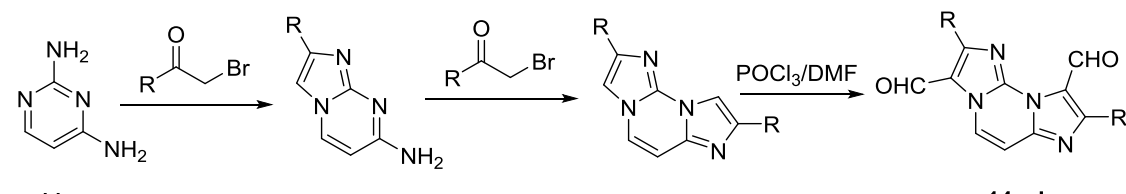

11

$12 a, b$

$13 a, b$

14a, b

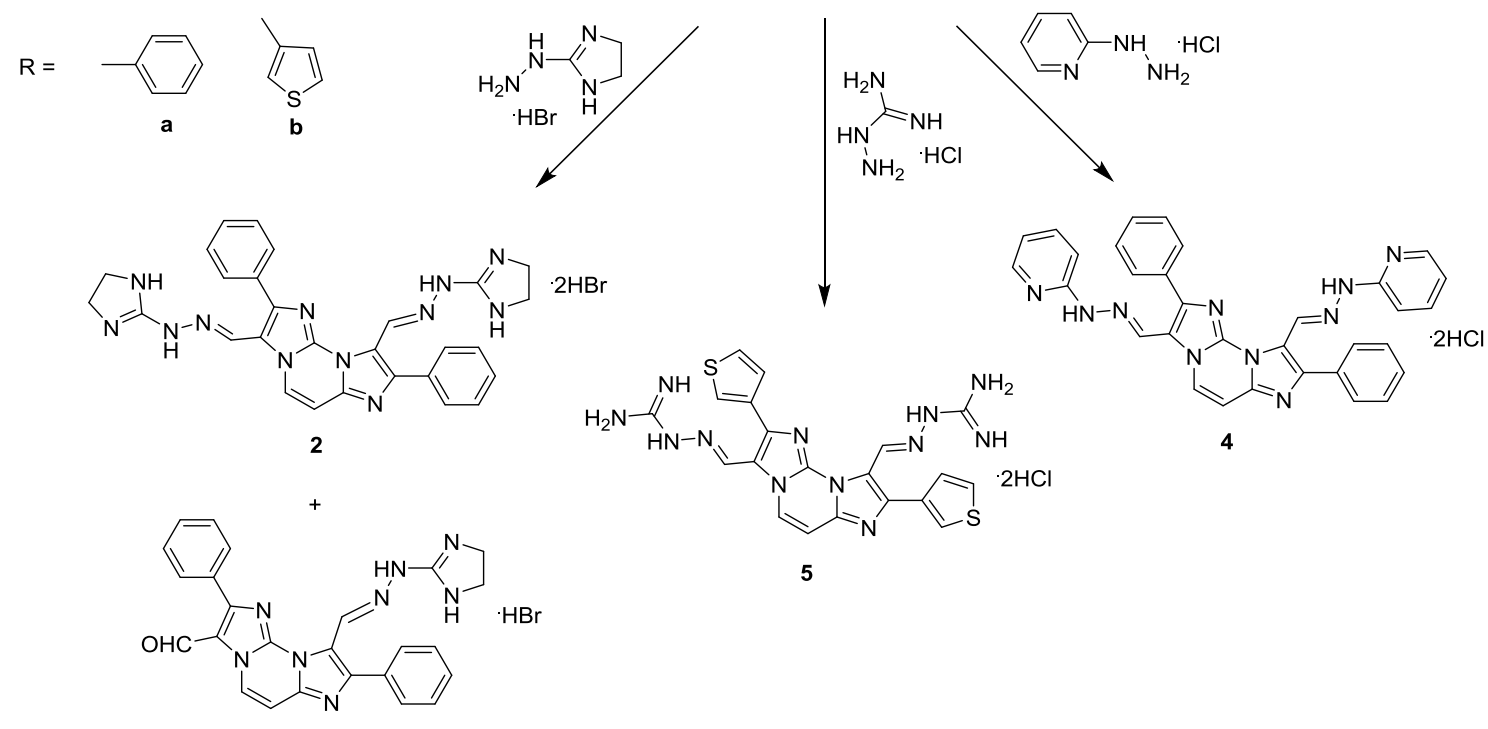

3

Scheme 1. Synthetic route for hydrazones 2-5. 

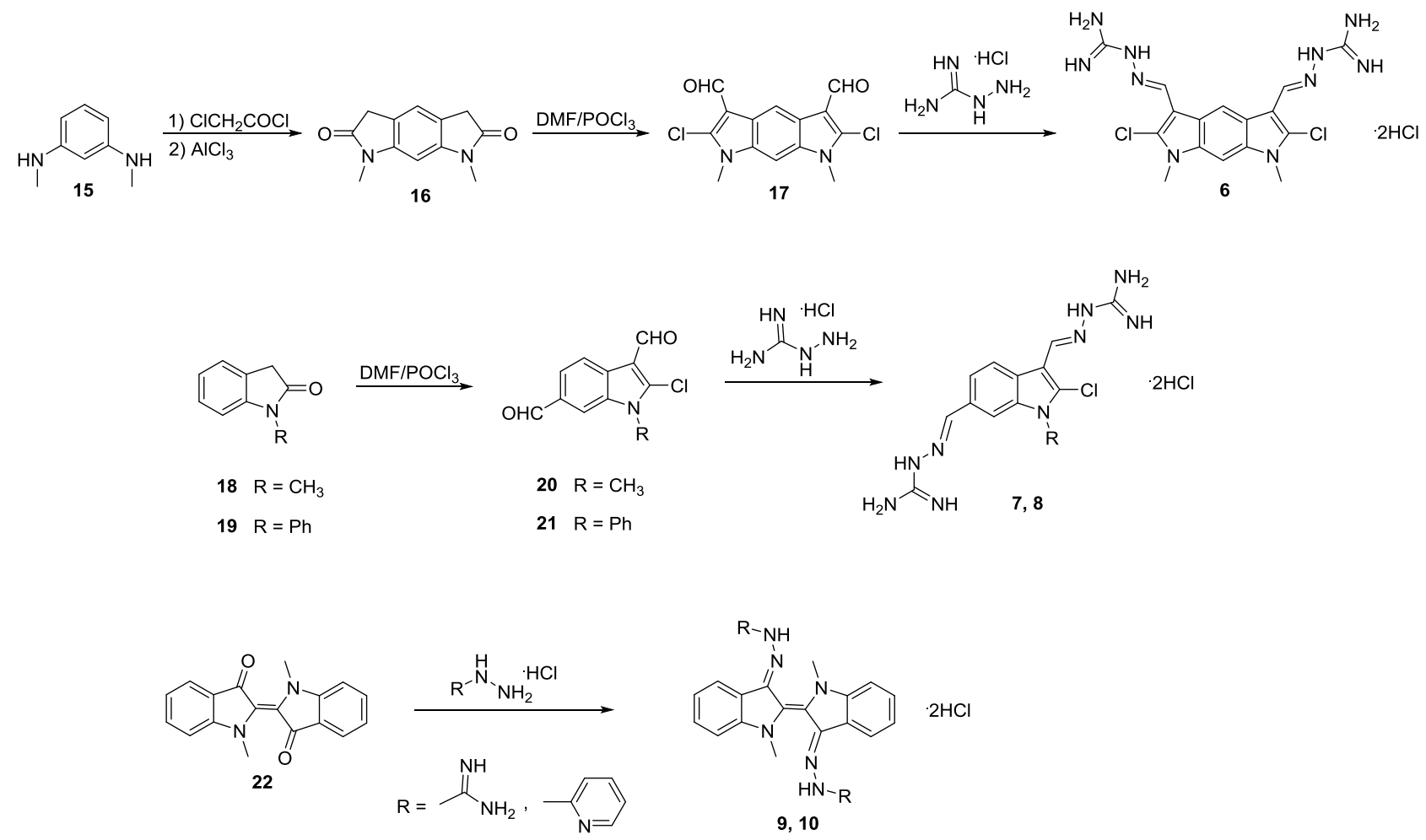

Scheme 2. Synthetic route for hydrazones 6-10. 


\section{TABLES}

Table 1. Ligand-induced thermal stabilization of G4 and duplex DNAs measured by CD melting experiments.

\begin{tabular}{|c|c|c|c|c|c|c|c|}
\hline \multicolumn{8}{|c|}{$\Delta \mathbf{T}_{\mathbf{m}}\left({ }^{\circ} \mathbf{C}\right)^{a}$} \\
\hline Compound & c-kit1 ${ }^{b}$ & c-kit2 ${ }^{c}$ & c-myc ${ }^{c}$ & Tel23-p ${ }^{b}$ & Tel23 $^{b}$ & Tel26 $^{b}$ & ds12 ${ }^{b}$ \\
\hline $\mathbf{1}^{d}$ & $>15.0$ & $>20.0$ & $>20.0$ & $>20.0$ & -10.0 & -4.5 & 0.1 \\
\hline 2 & 1.6 & $>20.0$ & $>15.0$ & 10.8 & -14.0 & -8.9 & 1.3 \\
\hline 3 & 2.7 & 9.5 & $>20.0$ & 9.1 & -2.4 & -3.0 & -0.8 \\
\hline 4 & 0.4 & 0.0 & -0.2 & 1.3 & -1.0 & -1.6 & 0.9 \\
\hline 5 & $>15.0$ & $>20.0$ & $>20.0$ & $>20.0$ & -4.9 & -6.5 & 3.5 \\
\hline 6 & $>15.0$ & $>15.0$ & $>20.0$ & $>20.0$ & 3.0 & 1.3 & $\mathrm{ND}^{e}$ \\
\hline 7 & $>15.0$ & $>20.0$ & $>20.0$ & $>20.0$ & 6.0 & 5.8 & $\mathrm{ND}^{e}$ \\
\hline 8 & $>15.0$ & $>15.0$ & $>20.0$ & $>20.0$ & 5.6 & 5.1 & $\mathrm{ND}^{e}$ \\
\hline 9 & 0.9 & 8.2 & 11.0 & 7.7 & -0.5 & 0.2 & -0.8 \\
\hline 10 & 1.5 & 2.0 & 1.6 & 4.0 & -2.5 & -2.0 & -0.7 \\
\hline
\end{tabular}


Table 2. Ligand-induced thermal stabilization of labeled G4-forming sequences evaluated by FRET melting analyses.

\begin{tabular}{lrrr}
\hline \multirow{3}{*}{ Compound } & \multicolumn{3}{c}{$\Delta \mathbf{T}_{\mathbf{m}}\left({ }^{\circ} \mathbf{C}\right)^{a}$} \\
\cline { 2 - 4 } $\mathbf{2}$ & Fckit2T $^{b}$ & FcmycT $^{b}$ & F21T-p $^{c}$ \\
$\mathbf{3}$ & $>20.0$ & $>15.0$ & $>15.0$ \\
$\mathbf{5}$ & $\approx 15.0$ & $>20.0$ & 7.0 \\
\hline
\end{tabular}

${ }^{a} \Delta \mathrm{T}_{\mathrm{m}}$ represents the difference in melting temperature $\left[\Delta \mathrm{T}_{\mathrm{m}}=\mathrm{T}_{\mathrm{m}(\mathrm{G} 4+4 \text { ligand }}\right.$ equiv.) $\left.-\mathrm{T}_{\mathrm{m}(\mathrm{G} 4)}\right] . \mathrm{T}_{\mathrm{m}}$ values of $\mathrm{G} 4 \mathrm{~s}$ alone: Fckit2T $=66.3 \pm 1.0{ }^{\circ} \mathrm{C}$; FcmycT $=68.6 \pm 1.0{ }^{\circ} \mathrm{C} ; \mathrm{F} 21 \mathrm{~T}-\mathrm{p}=67.1 \pm 1.0^{\circ} \mathrm{C}$. All experiments were duplicated and the values reported are average of two measurements. ${ }^{b} 20 \mathrm{mM} \mathrm{KCl}$ buffer. ${ }^{c} 100 \mathrm{mM} \mathrm{KCl}$ buffer.

Table 3. Cytotoxic activity of selected hydrazone derivatives in human U2OS and HCT116 cells.

\begin{tabular}{lcccc} 
& \multicolumn{2}{c}{$\mathbf{I C}_{\mathbf{5 0}}(\boldsymbol{\mu M}) \mathbf{1}$ hour } & \multicolumn{2}{c}{$\mathbf{I C}_{\mathbf{5 0}}(\boldsymbol{\mu M}) \mathbf{2 4}$ hours } \\
\hline Compound & \multicolumn{1}{c}{ U2OS } & HCT116 & U2OS & HCT116 \\
\hline $\mathbf{1}$ & $101.0 \pm 1.63$ & $35.07 \pm 1.06$ & $15.97 \pm 1.41$ & $5.12 \pm 1.05$ \\
$\mathbf{3}$ & $5.73 \pm 1.48$ & $4.18 \pm 1.07$ & $0.845 \pm 0.001$ & $0.407 \pm 0.106$ \\
$\mathbf{1 4 a}$ & $45.23 \pm 2.05$ & $16.79 \pm 1.06$ & $9.16 \pm 1.44$ & $4.06 \pm 1.07$ \\
\hline
\end{tabular}

The concentrations killing $50 \%$ of cells $\left(\mathrm{IC}_{50}\right)$ are means $\pm \mathrm{SE}$ of two independent experiments performed in triplicates.

\section{TOC}

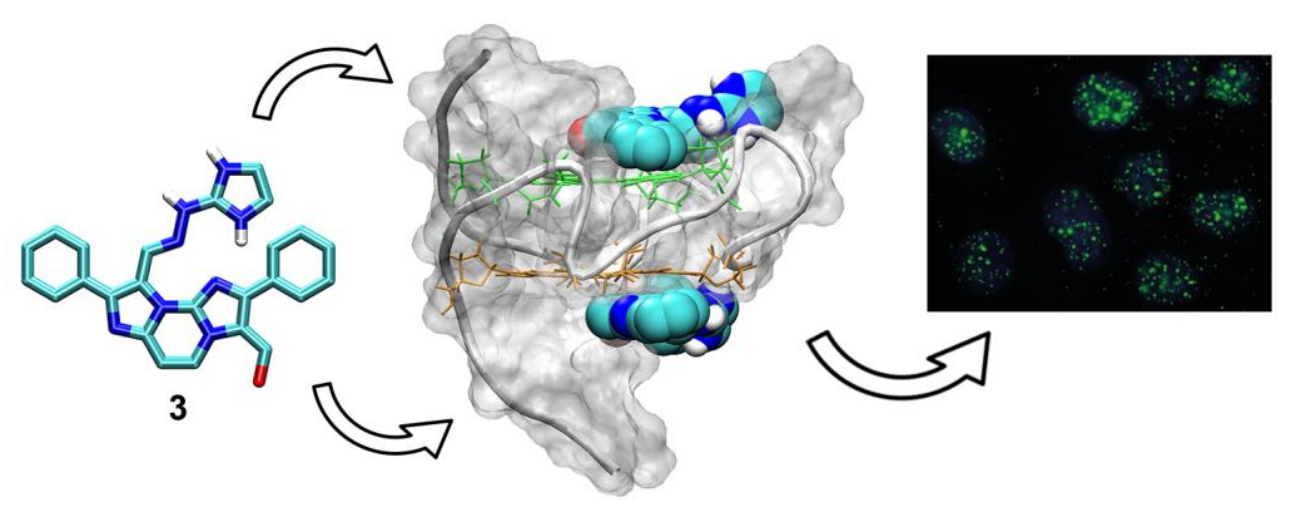

